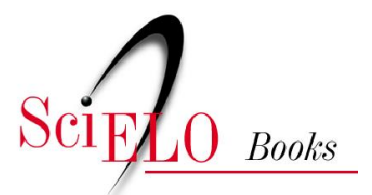

\title{
Processo participativo na construção de indicadores hidroambientais para bacias hidrográficas
}

\author{
José Ribamar Marques de Carvalho \\ Wilson Fadlo Curi \\ Waleska Silveira Lira
}

\section{SciELO Books / SciELO Livros / SciELO Libros}

CARVALHO, JRM., CURI, WF., and LIRA, WS. Processo participativo na construção de indicadores hidroambientais para bacias hidrográficas. In: LIRA, WS., and CÂNDIDO, GA., orgs. Gestão sustentável dos recursos naturais: uma abordagem participativa [online]. Campina Grande: EDUEPB, 2013, pp. 31-80. ISBN 9788578792824. Available from SciELO Books $<\underline{\text { http://books.scielo.org }>}$

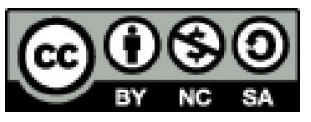

All the contents of this work, except where otherwise noted, is licensed under a Creative Commons Attribution-Non Commercial-ShareAlike 3.0 Unported.

Todo o conteúdo deste trabalho, exceto quando houver ressalva, é publicado sob a licença Creative Commons Atribuição Uso Não Comercial - Partilha nos Mesmos Termos 3.0 Não adaptada.

Todo el contenido de esta obra, excepto donde se indique lo contrario, está bajo licencia de la licencia Creative Commons Reconocimento-NoComercial-CompartirIgual 3.0 Unported. 


\title{
Processo participativo na construção de indicadores hidroambientais para bacias hidrográficas
}

\author{
José Ribamar Marques de Carvalho \\ Wilson Fadlo Curi \\ Waleska Silveira Lira
}

\section{Introdução}

O interesse e a preocupação sobre questões ambientais assumiram grande importância no debate científico e político, de maneira mais intensificada a partir das décadas de 60 e 70, onde surgiram movimentos ambientalistas, regulamentações, organizações não-governamentais, dentre outros, fruto principalmente do atual contexto em que se encontram os atuais sistemas convencionais de gestão de recursos naturais de uso compartilhado.

Apesar do estágio embrionário de desenvolvimento do novo campo interdisciplinar de pesquisas sobre meio ambiente, bem como do caráter fortemente especulativo do debate social criado em torno do agravamento dos conflitos ambientais, as evidências empíricas já acumuladas sobre os impactos ecológicos das ações humanas parecem colocar, em xeque, as formas usuais de gestão das relações sociedade-natureza. (VIEIRA; WEBER, 2002, p. 17)

A gestão atual dos recursos renováveis coloca em jogo inúmeras disciplinas associadas aos campos das ciências sociais, naturais e cognitivas. As questões que os autores levantam estão ancoradas na percepção de uma realidade mais imediata, que motiva o engajamento nesse domínio 
de pesquisa e constitui tanto o seu desafio central quanto a sua finalidade básica - ou seja, novas perspectivas que se abrem a um esforço de integração interdisciplinar. (VIEIRA; WEBER, 2002)

Estamos diante de uma crise socioambiental que deveria ser pensada em sua dimensão complexa e sistêmica (POLICARPO; SANTOS, 2008). Para as autoras, os sistemas convencionais de gestão de recursos naturais de uso compartilhado não consideram o potencial contido nos diferentes sistemas de autoridade construídos e administrados no nível local nem os diferentes tipos e interesses de atores sociais chaves para a gestão.

Notadamente, existe um crescente entendimento diante da necessidade de compreender melhor as diferenças nos processos e arranjos sociais, principalmente devido aos limites das práticas sociais e das atitudes dos diversos atores envolvidos no atual contexto dos recursos hídricos.

Nesse contexto, a gestão de bacias hidrográficas assume crescente importância no Brasil, à medida que aumentam os efeitos da degradação ambiental sobre a disponibilidade de recursos hídricos. A efetivação do processo de gestão em bacias hidrográficas, de acordo com a lei 4.933/97, ainda é embrionária, e a prioridade dos organismos de bacia se centra na criação dos instrumentos necessários para a gestão. (JACOBI, 2005)

O sistema é inovador e rompe com práticas profundamente arraigadas de planejamento tecnocrático e autoritário, devolvendo poder para as instituições descentralizadas de bacia. Os alcances das experiências têm sido desiguais, destacando a constituição de organismos colegiados de tomada de decisão. Até 2003, mais de uma década após a aprovação da primeira lei das águas no país, nenhum sistema foi operacionalizado por completo. (JACOBI, 2005)

Dentro desse contexto, entende-se que os indicadores de sustentabilidade hidroambiental aparecem como ferramentas capazes de subsidiar o monitoramento da operacionalização do desenvolvimento sustentável, tendo como função principal a revelação de informações sobre o estado das diversas dimensões (ambientais, econômicas, socioeconômicas, culturais, institucionais etc) que compõem o desenvolvimento sustentável da gestão hídrica na sociedade. 
Silva et. al. (2010) destacam que os indicadores de sustentabilidade são utilizados como ferramenta padrão em diversos estudos nacionais e internacionais, facilitando a compreensão das informações sobre fenômenos complexos, e atua como base para análise do desenvolvimento que abrange diversas dimensões (nelas incluídos fatores econômicos, sociais, culturais, geográficos e ambientais), uma vez que permite verificar os impactos das ações humanas no ecossistema.

Esse cenário acaba por refletir na busca por mecanismos de gestão capazes de inserir em seu contexto dimensões ambientais, sociais, econômicas, institucionais, éticas etc, de maneira integrada e participativa no intuito de minimizar os efeitos das políticas vigentes fortemente influenciadas pelo caráter disciplinar, o que traz à tona a importância de incluir a percepção diferenciada dos vários atores sociais e das institucionais envolvidas na busca do desenvolvimento sustentável e em especial dos recursos hídricos.

Para nortear o presente estudo, tomou-se como base os estudos realizados por Guimarães (2008), Magalhães Júnior et. al. (2003), Vieira e Studart (2009), Magalhães Júnior (2010), bem como as contribuições de Vieira e Weber (2002), Vieira (2003), Berkes (2005), Godard (2002), Ollagnon (2002).

Dada tais premissas acerca da importância sobre essa temática e, também, por sabermos que muito ainda precisa ser feito para melhorar o cenário hídrico atual, surge o seguinte questionamento: Como construir indicadores de sustentabilidade hidroambientais a partir da participação de atores sociais da gestão hídrica?

No intuito de atender à problemática proposta, fica definido o seguinte objetivo: analisar aspectos relevantes que devem ser levados em consideração na construção de indicadores hidroambientais para bacias hidrográficas de modo que possa contribuir para uma gestão participativa da gestão hídrica.

Este ensaio teórico está estruturado da seguinte forma: inicialmente é feita a revisão da literatura acerca dos temas que norteiam a temática; em seguida, são propostos indicadores para uma futura aplicação junto a especialistas da área e finalmente estão expostas as considerações finais do estudo. 


\section{Desenvolvimento Sustentável}

Antes de abordar a importância dos índices e indicadores, é importante compreender melhor o significado do conceito de desenvolvimento sustentável de uma maneira mais geral, uma vez que este tema tem sido amplamente discutido por pesquisadores e tomadores de decisão nas mais variadas áreas relacionadas ao uso e apropriação de recursos naturais.

As reflexões sobre o tema desenvolvimento, juntamente com o aumento da pressão exercida pela antroposfera sobre a ecosfera, levaram ao crescimento da consciência sobre os problemas ambientais gerados por padrões de vida incompatíveis com o processo de regeneração do meio ambiente, principalmente a partir da década de 1970, e culmina o surgimento do conceito de desenvolvimento sustentável, e consequentemente o desenvolvimento e a aplicação de sistemas de indicadores ou ferramentas de avaliação que procuram mensurar a sustentabilidade. (VAN BELLEN, 2006)

Van Bellen (2006) discute a crise ecológica a partir de seus fundamentos históricos mostrando os maiores problemas ambientais contemporâneos (entre os anos de 1960 e 1980) e sua influência na relação existente entre sociedade e meio ambiente, evidenciando o início da tomada de consciência sobre esses problemas até o presente momento e a sua evolução de maneira mais crítica, mais globalizada e menos localizada, subsidiando o surgimento de novas alternativas de relacionamento da sociedade contemporânea com seu ambiente, procurando reduzir os impactos que ela produz sobre o meio que a cerca.

Atualmente existe, no contexto da sociedade civil, uma nova consciência sobre a crise ambiental, fruto de mudanças ocorridas, percepção por parte da sociedade civil e dos especialistas da área no que se refere à gestão ambiental.

Van Bellen (2006), Leff (2000) e Brüseke (2009) evidenciam que esse aspecto pode ser claramente percebido quando se observam as mudanças na concepção de desenvolvimento até chegar ao conceito de desenvolvimento sustentável. Van Bellen (2006) e Brüseke (2009) fazem um relato histórico que demonstra as estações importantes da discussão sobre um conceito alternativo de desenvolvimento sustentável: 1) A Contribuição do Clube de Roma - Limites do crescimento; Conferência de Estocolmo (1972) sobre ambiente humano; 
2) Ecodesenvolvimento - em que Van Bellen coloca a contribuição de Ignacy Sachs (1976), quando formulou os princípios básicos dessa nova visão do desenvolvimento. Todavia, percebe-se a ausência de outros estudiosos como, por exemplo, Maurice Strong (1973) que caracterizou uma concepção alternativa de política do desenvolvimento; Glaeser e Uyasulu (1984) que os debates sobre o ecodesenvolvimento prepararam a adoção posterior do desenvolvimento sustentável, que estão presentes em Brüseke (2009, p. 29-37). 3). A Declaração de Cocoyok (1974) - resultado de uma reunião da UNCTAD (Conferências das Nações Unidas sobre Comércio-Desenvolvimento) e do UNEP (Programa de Meio Ambiente das Nações Unidas). 4) O Relatório Dag-Hammarsjöld (1975) - as proposições de Cocoyok foram aprofundadas no relatório final de um projeto da Fundação Dag-Hammarsjöld com participação de pesquisadores e políticos de 48 países. 5) Sustentabilidade com Estratégia de Desenvolvimento: O Relatório Brundtland - sublinha a interligação entre a economia, tecnologia, sociedade e política e chama também atenção para uma nova postura ética, caracterizada pela responsabilidade tanto entre as gerações quanto entre os membros contemporâneos da sociedade atual. 6) A Rio-92 - que contribuiu para aumentar o grau de consciência sobre o modelo de desenvolvimento adotado mundialmente e também sobre as limitações que ele apresenta.

Notadamente o que se observa, segundo os autores, é que o surgimento de desenvolvimento sustentável traz uma nova percepção sobre a crise ambiental, mas, também, uma série de questões conceituais. Dentro desse contexto, destaca as dificuldades encontradas na operacionalização desse elemento a partir das diferenças conceituais e práticas que existem sobre o tema.

Muito embora o conceito e o discurso da sustentabilidade possam ser identificados em diversas situações e contextos históricos, suas expressões mais recentes são observadas nos princípios da década de 70 do século passado (conforme destacado anteriormente). Sachs (2000) e Van Bellen (2006) mostram que existem diversas sugestões, controvérsias, sobre as dimensões que se relacionam com a sustentabilidade que sejam:

Sustentabilidade econômica: avaliada a partir da sustentabilidade social propiciada pela organização da vida material, dentro do contexto de sustentabilidade forte e fraca, ambas baseadas no fato de que a humanidade deve preservar capital natural para as futuras gerações, enfatiza ainda, de maneira crítica, a importância de se discutir a sustentabilidade a partir da contabilidade e da responsabilidade. Para o autor, quando 
cita Bartelmus (1995), os meios tradicionais para medir custo e capitais, os sistemas nacionais de contas, têm falhado por negligenciar, por um lado, a escassez provocada pela utilização dos recursos naturais, que prejudica a produção sustentável da economia e, por outro, a degradação da qualidade ambiental e as consequências que ela tem sobre a saúde e o bem-estar humanos, dentre outros aspectos;

Sustentabilidade social: ancorada no princípio da equidade na distribuição de renda e dos bens, no princípio da igualdade de direitos à dignidade humana e no princípio da solidariedade dos laços sociais;

Sustentabilidade ambiental: ancorada no princípio da solidariedade com o planeta e suas riquezas e com a biosfera que o envolve;

Sustentabilidade geográfica: norteada pelo alcance de uma equanimidade (serenidade de espírito) nas relações inter-regionais e na distribuição populacional entre o rural/urbano e o urbano;

Sustentabilidade cultural: relacionada ao caminho da modernização sem o rompimento da identidade cultural, considerada por Sachs (2000) e corroborada por Bellen (2006) como a mais difícil de ser concretizada.

Nesse sentido, o que se observa a partir dos estudiosos da área é que os movimentos dentro dessa temática têm aumentado a influência desse conceito, posto existir uma grande diversidade de conceitos dentro da complexidade do termo desenvolvimento sustentável. Sob esse aspecto, entende-se que tais esforços e empenhos emergem no intuito de sanar um conjunto de contradições expostas e não respondidas pelos modelos anteriores de desenvolvimento de maneira que seja viável entender que o desenvolvimento sustentável é o meio, e a sustentabilidade é o fim.

\section{Peculiaridades dos Indicadores hidroambientais para Bacias Hidrográficas}

O maior desafio, quando se trata de discutir a questão da sustentabilidade, é o de compatibilizar o crescimento econômico com a preservação ambiental e justiça social. Para isso, o gerenciamento do conhecimento no uso dos indicadores de sustentabilidade pode ser um instrumento adequado para tais evidências, principalmente porque nestes sistemas de indicadores estão contidas todas as informações pertinentes à situação econômica, social, e ambiental de um espaço geográfico em um determinado período. (LIRA, 2008. 72) 
Sendo assim, os indicadores de sustentabilidade hidroambientais aparecem como ferramentas capazes de subsidiar o monitoramento da operacionalização do desenvolvimento sustentável hídrico, tendo como função principal a revelação de informações sobre o estado das diversas dimensões (ambientais, econômicas, socioeconômicas, culturais, institucionais etc) que compõem o desenvolvimento sustentável do sistema que se pretende conhecer, monitorar e aprimorar.

Os indicadores de sustentabilidade são utilizados como ferramenta padrão em diversos estudos nacionais e internacionais, facilitando a compreensão das informações sobre fenômenos complexos, e atuam como base para análise do desenvolvimento que abrange diversas dimensões (nelas incluídas fatores econômicos, sociais, culturais, geográficos e ambientais), uma vez que permite verificar os impactos das ações humanas no ecossistema. (SILVA et. al., 2010, p. 242).

As definições mais comuns de indicadores e a terminologia associada a essa área são particularmente confusas, tanto em relação à definição de indicadores quanto a outros conceitos associados como: índice, meta e padrão. O objetivo dos indicadores é agregar e quantificar informações de um modo que sua significância fique mais aparente, simplificando informações sobre fenômenos complexos tentando melhorar com isso o processo de comunicação. Percebe-se que os indicadores podem ser quantitativos ou qualitativos, existindo autores que definem que os mais adequados para a avaliação de experiências de desenvolvimento sustentável deveriam ser mais qualitativos, em função das limitações explícitas e implícitas que existem em relação a indicadores simplesmente numéricos, muito embora, em alguns casos, avaliações qualitativas podem ser transformadas numa notação quantitativa. (VAN BELLEN, 2006).

O que se percebe, no discurso exposto, é que a utilização de indicadores é uma maneira intuitiva de monitorar complexos sistemas, que a sociedade considera importante e que devem ser controlados (MEADOWS, 1998 apud VAN BELLEN, 2006), capazes de evidenciar elementos importantes da maneira como a sociedade entende seu mundo, toma duas decisões e planeja a sua ação. Os valores, e logicamente os indicadores, estão inseridos dentro de culturas específicas, muito embora existam armadilhas na sua utilização e ainda que estejam inseridos dentro de culturas específicas, realçando o que está acontecendo em determinada sociedade. Notadamente, observa-se que existem distintas definições de indicadores e especificamente sobre indicadores hidroambientais, como por exemplo, o conceito exposto por Garcias 
(2001) e reforçado por Beck et. al. (2009), no qual, os indicadores de sustentabilidade devem ser usados para mensurar o quanto uma nação, um empreendimento ou atividade podem ser sustentáveis nos âmbitos sociais, econômicos e ambientais e representam ferramentas de apoio à decisão. Ou que os indicadores de sustentabilidade ambiental representam uma metodologia indicada para avaliação do comportamento ambiental. Ou ainda, o conceito de Tunstall (1992), Castro (2004) que mostram a sua importância quando afirmam que serve para monitorar, estudar, prever ou comparar condições ou tendências, comparar lugares, situações ou alternativas, ou ainda advertir sobre algum impacto/ação ou guiar decisões.

Fica evidente que muito embora existam várias definições acerca da terminologia utilizada, ainda permanece a falta de consenso entre os autores, emergindo desta forma a necessidade de desenvolver uma definição mais rigorosa e unificada de indicador no que se refere à temática ambiental, visto que a grande maioria dos sistemas de indicadores existentes e utilizados foi desenvolvida por razões específicas, sejam elas ambientais, econômicas, de saúde e sociais e não podem ser considerados indicadores de sustentabilidade em si, mesmo dispondo de um potencial representativo dentro do contexto do desenvolvimento sustentável conforme defende Van Bellen (2006).

Alguns cuidados-chave devem ser tomados quando da escolha de indicadores de sustentabilidade hidroambientais, uma vez que, diferentes tipos de indicadores podem, em determinadas situações, ser relevantes em diferentes escalas e, também, podem perder o seu sentido quando utilizados sem o devido cuidado em escalas não apropriadas.

Van Bellen (2006) mostra outro aspecto que deve ser levado em conta na discussão, que consiste na dimensão do tempo podendo ser escalares (número simples gerado da agregação de dois ou mais valores) e vetoriais (geração de uma variável com magnitude e direção de característica bidirecional - tendência de futuro com viés holístico), além dos valores existentes na sua escolha, explícitos (tomados conscientemente e que compreendem uma parte fundamental no processo de criação de indicadores) e os implícitos (decorrem de aspectos que não são facilmente observáveis e que são, na sua maioria, inconscientes e relacionados a características pessoais e de uma determinada sociedade).

Exaustivamente elenca outras características e/ou requisitos como ponderação, contexto geográfico, temporal, econômico, local, cultura, 
compreensibilidade, mensuráveis, ter disponibilidade de dados, metodologia para coleta e processamento de dados, viabilidade financeira, humana e técnica e ainda aceitação política.

Especificamente nos Comitês de Bacias Hidrográficas (CBHs), existe uma diversidade de conhecimentos, opiniões e valores envolvidos que leva a um contínuo processo de evolução baseado na diferenciação de estrutura, mas, ao mesmo tempo, na integração de funções. A diferenciação significa, segundo Guimarães Júnior (2010, p. 397), "diferenças de atitudes e de comportamento e não apenas de fracionamento... é preciso uma diversidade essencial de componentes." Assim, em função da diversidade humana presente nos $\mathrm{CBHs}$, a riqueza do processo decisório participativo resulta, em grande parte, da compatibilidade entre os conhecimentos cognitivos e os conhecimentos técnicos dos atores sociais. (MAGALHÃES JÚNIOR, 2010).

$\mathrm{O}$ autor reforça afirmando que, em função da diversidade humana nos $\mathrm{CBH}$, a riqueza do processo decisório participativo resulta, em grande parte, da compatibilidade entre os conhecimentos cognitivos e os conhecimentos teóricos dos atores sociais. As informações técnicas são importantes para que o processo decisório possa ser coerente com os princípios racionais, não evoluindo apenas empiricamente com o objetivo de apaziguamento social dos atores envolvidos. Certas experiências mostram que a mobilização coletiva pode ocorrer mais em função de ajustes cognitivos do que em função de argumentos científicos e, portanto, os $\mathrm{CBH}$ devem buscar a conciliação entre ambos para que as decisões sejam socialmente aceitas e comprovadas.

\section{Modelos de Indicadores de sustentabilidade para recursos hídricos}

A literatura nacional e internacional evidencia algumas experiências em relação à utilização de modelos de indicadores de sustentabilidade como maneira de subsidiar o gerenciamento das bacias hidrográficas. A seguir, estão evidenciados alguns estudos que foram realizados com a utilização de indicadores na gestão dos recursos.

A Agência de Proteção Ambiental dos EUA (US Environmental Protection Agency) tem desenvolvido um Índice de Bacias Hidrográficas (IWI - Index of Watershed Indicators) no intuito de avaliar a qualidade ambiental das bacias hidrográficas do mundo. O IWI foi elaborado a 
partir de dois tipos de indicadores: indicadores de condição e indicadores de vulnerabilidade. Os indicadores de condição buscam revelar a qualidade da água nas bacias hidrográficas, enquanto os indicadores de vulnerabilidade são projetados para fornecer uma indicação de onde surge a poluição nas bacias hidrográficas, bem como outros potenciais problemas que as bacias hidrográficas enfrentam. (HIGGINS; TRULIO, 2003) $)^{1}$

O Instituto Baía (The Bay Institute) desenvolveu um índice composto por 36 índices para avaliar o grau das condições da região da Baía de São Francisco (San Franscisco Bay Index) em relação aos recursos ecológicos, como as atividades humanas estavam ajudando ou prejudicando a baía e como os moradores que usam os recursos da baía tiveram sua saúde afetada. Esses indicadores foram combinados em oito índices que forneceram o perfil da bacia. (GUIMARÃES, 2008).

Magalhães Júnior (2010) sugere uma série de indicadores ambientais potencialmente úteis à gestão da água no Brasil, envolvendo 7 indicadores relacionados à dimensão de cobertura vegetal, 4 indicadores relacionados ao estado qualitativo dos estoques hídricos, 14 indicadores relacionados a dinâmica fluvial e riscos de não atendimento às demandas, 21 indicadores relacionados ao estado qualitativo da água, 13 indicadores relacionados às pressões ou impactos sobre as águas e ambientes aquáticos, 15 indicadores acerca das pressões de disponibilidade hídrica (redução dos estoques hídricos), 5 indicadores relacionados às pressões sobre a qualidade das águas (pressões agrícolas e industriais), 25 indicadores acerca de indicadores de respostas/desempenho do sistema de gestão da água, e 11 indicadores de desempenho do sistema de gestão quanto aos aspectos legais, institucionais, financeiros e de fiscalização.

A experiência francesa, na utilização de indicadores ambientais, na gestão da água, evidencia indicadores prioritários adotados, no país, nos quais se dividem em quatro principais categorias: indicadores de

1 The US Environmental Protection Agency (EPA) has developed an Index of Watershed Indicators (IWI) to assess the health of watersheds nationwide. As a federal enforcement agency, the EPA can regulate the impacts that occur as a result of human actions. The IWI has divided its indicators into two distinct types: condition and vulnerability indicators. The condition indicators reveal existing water quality in watersheds nationwide while the vulnerability indicators are designed to provide an indication of where pollution arises in watersheds as well as other potential problems that impact watersheds 
pressão (quatro eixos temáticos: poluição doméstica e industrial; produção de resíduos sólidos; poluição agrícola; degradação dos meios aquáticos; disponibilidade hídrica), indicadores de estado das águas (cinco eixos relacionados à qualidade físico-química; qualidade química de águas marítimas; qualidade biológica da água de consumo humano; qualidade ecológica da água; disponibilidade hídrica), indicadores de resposta dos serviços de água e esgotos (quatro eixos relacionados ao nível de operacionalidade e avanço de documentos programáticos; modos de gestão; desempenho dos serviços de água; desempenho dos serviços de esgotos), e indicadores de resposta dos recursos hídricos (a partir dos eixos de conformidade da qualidade de água físico-química da água de contato primário; conformidade da qualidade de água química das águas marinhas; conformidade da qualidade biológica da água de consumo humano; gestão dos meios aquáticos e meios associados). (MAGALHÃES JÚNIOR, 2010, p. 274-277).

$\mathrm{Na}$ França, cada agência de água adota e elabora, desde o ano de 2000, um painel de indicadores (prioritários e/ou operacionais) no nível de sua respectiva bacia: são os Tableaux de Bord de Suivi des SDAGE (Schéma Directeur d'Aménagement et de Gestion des eaux). Esse painel é usado para o monitoramento anual das ações propostas nos planos diretores de bacias. (MAGALHÃES JÚNIOR et. al., 2003, p. 53).

Guimarães (2008) desenvolveu uma proposta de um sistema de indicadores de desenvolvimento sustentável para bacias hidrográficas a ser aplicado no Brasil. Nessa metodologia, a autora propõe um índice agregado com 8 indicadores relacionados à dimensão social, 20 relacionados à dimensão ambiental, 8 de natureza econômica e 4 relacionados à dimensão institucional.

O Community Information Center, Interrain Pacific e Ecotrust estão empenhados em ajudar os cidadãos, líderes de comunidades e pessoas de negócio a saúde e a riqueza da região do Columbia Pacific. Eles desenvolveram o "Columbia-Pacific Indicators: Assessing Community Sustainability for the Region, em 1996, que avalia indicadores de comunidade sustentável para a bacia do Rio Columbia nos Estados Unidos a partir de três dimensões (ambiental, econômica e social). (GUIMARÃES, 2008)

Vieira e Studart (2009) propuseram um modelo de Índice de Sustentabilidade Hidroambiental (ISHA) para Ambientes Serranos no Semiárido do Estado do Ceará - a APA (Área de Proteção Ambiental) 
do Maciço Baturité. O modelo estrutural baseou-se na abordagem Pressão-Estado-Resposta (OECD). O ISHA mostra a posição relativa e a posição absoluta de cada município dos seguintes índices: Índice Hídrico (8 indicadores), Índice Físico (4 relacionados), Índice Biótico (4 relacionados) e Índice Antrópico (12 indicadores).

Guimarães Jr, Cordeiro Neto e Nascimento (2003) obtiveram e interpretaram os resultados de um painel de especialistas (técnica Delphi) no sentido de avaliar a importância dos indicadores na gestão de águas no Brasil, no intuito de identificar os indicadores prioritários pelos especialistas, e, por consequência, os eixos prioritários de gestão na realidade atual.

\section{Apropriação, uso e tomada de decisão em recursos hídricos}

A complexidade das decisões que fazem parte da gestão dos recursos hídricos decorre tanto das diferentes possibilidades de suprimento às demandas quanto das variabilidades destas demandas. (LANNA, 2002, p. 16)

As principais categorias de demandas de água estão inseridas em três classes segundo o autor:

1) Infraestrutura social: refere-se às demandas gerais da sociedade nas quais, a água é um bem de consumo final;

2) Agricultura e aquicultura: refere-se às demandas de água como bem de consumo intermediário visando à criação de condições ambientais adequadas para o desenvolvimento de espécies animais ou vegetais de interesse da sociedade;

3) Industrial: demandas para atividades de processamento industrial e energético nas quais a água entra como bem de consumo intermediário.

Quanto à natureza da utilização, existem três possibilidades segundo Lanna (2002):

1) Consuntivo: refere-se aos usos que retiram a água de sua fonte natural diminuindo suas 
disponibilidades quantitativas, espacial e temporalmente (usos domésticos, agricultura, pecuária, irrigação, processamento industrial, termoeletricidade, transporte hidráulico, dentre outros).

2) Não-consuntivo: refere-se aos usos que retornam à fonte de suprimento, praticamente a totalidade da água utilizada, podendo haver alguma modificação no seu padrão temporal de disponibilidade quantitativa (navegação, recreação, piscicultura, mineração, hidroeletricidade, dentre outros).

3) Local: refere-se aos usos que aproveitam a disponibilidade de água em sua fonte sem qualquer modificação relevante, temporal ou espacial, de sua disponibilidade quantitativa.

Para o autor, existem alguns tipos de valores sociais que devem ser considerados em relação às demandas ambientais dos recursos hídricos, que sejam:

- O valor de uso potencial da água é aquele derivado do seu uso potencial para promover o bem-estar da sociedade. No caso em tela, a referência é a de um uso futuro provável. Esta classe de valor pode ser associada à estratégia de preservação de opções, tendo em vista a incerteza inerente ao futuro de longo prazo, que poderá tornar certos bens relacionados com a água com valor social expressivo.

- Valor intrínseco é aquele associado aos recursos hídricos, independente da possibilidade de seu uso, corrente ou potencial, para promover o bem-estar da sociedade. Aceita-se aqui a premissa filosófica de que não cabe ao ser humano a valoração do ambiente, pois ele possui um valor em si.

- Conflitos de uso da água que, no passado, as pequenas necessidades hídricas podiam ser atendidas pelas disponibilidades naturais sem maiores investimentos que aqueles necessários para a captação da água. $\mathrm{O}$ desenvolvimento econômico foi mais intenso das regiões de relativa abundância da água. $\mathrm{O}$ aumento populacional e do próprio desenvolvimento econômico acabaram por reduzir as disponibilidades em alguns locais e por tornar atraentes outras regiões carentes de água, exigindo maiores investimentos para obtê-las. 
Como a sociedade moderna ampliou consideravelmente a diversidade de usos, emergem, nesse cenário, demandas conflitantes e múltiplos usuários gerando conflitos de uso dos recursos hídricos e que podem ser classificados como: conflitos de destinação de uso (esta situação ocorre quando é utilizada para destinações outras que não aquelas estabelecidas por decisões políticas, fundamentadas ou não nos anseios sociais, que as reservariam para o atendimento de necessidades sociais, ambientais e econômicas); conflitos de disponibilidade qualitativa (situação típica de uso em corpos de água poluídos); e conflitos de disponibilidade quantitativa (situação decorrente do esgotamento da disponibilidade quantitativa devido ao uso intensivo). (LANNA, 2002, p. 22)

Nesse cenário, os modos de apropriação dos recursos hídricos atingiram níveis conflitantes, sejam eles em regiões mais desenvolvidas ou mais carentes. Além daqueles relacionados com a qualidade de água, notados nas bacias urbanizadas e industrializadas, existem também conflitos quantitativos. "Suas soluções exigem análises técnicas e institucionais de grande complexidade” (LANNA, 2002, p. 23).

Dentro deste panorama, observa-se a necessidade de buscar uma integração harmônica entre as partes envolvidas de maneira que o consenso possa surgir como uma alternativa no gerenciamento de tais conflitos e, consequentemente, o processo de decisório que envolve essas questões, vez que é imprescindível na análise da gestão ambiental (seja ela objetiva ou subjetiva) desconsiderar tais questões que assumem peculiaridades multifacetadas.

De acordo com Gomes et al. (2009), uma decisão precisa ser tomada sempre que estamos diante de um problema que possui mais de uma alternativa para sua solução. Mesmo quando, para solucionar um problema, possuímos uma única ação a tomar, temos as alternativas de tomar ou não essa ação. Concentrar-se no problema certo possibilita direcionar corretamente todo o processo.

Lyra (2008), por sua vez, quando cita Simon (1997), argumenta que decidir envolve a seleção de uma alternativa entre várias, cuja escolha depende do grau de racionalidade e objetividade do tomador de decisão. Por ser um processo subjetivo que envolve principalmente percepção e julgamento; para tomar uma decisão, o interessado usa todas as experiências adquiridas, crenças, valores, conhecimentos técnicos e habilidades, pois, quanto melhor ele compreender e interpretar 
os elementos envolvidos, melhor será sua decisão. É, portanto, uma tarefa que requer conhecimento, segurança e coerência. (LYRA, 2008, p. 7)

Muitos tomadores de decisão acreditam que suas decisões devem ser baseadas, principalmente, em fatos sólidos e em análises cuidadosas, mas outros confiam na intuição e na experiência, aparentemente indiferentes às suas necessidades de informação. No passado, ambos os grupos tinham sucesso, mas os tempos mudaram. Atualmente, a tomada de decisão é mais complexa, em razão da interação de variáveis internas e externas, do envolvimento de muitos decisores no processo de tomada de decisão, dos problemas de recursos e de oferta, das implicações de mercado, dos fatores ambientais, do rápido ritmo da mudança tecnológica e do impacto do crescimento e da diversificação da produção. Fundamentando-se no exposto, os decisores precisam obter e usar informação relevante, que aumente seu conhecimento e reduza sua incerteza, que seja útil, portanto, para desenvolver planos estratégicos e para alcançar objetivos desejados. (SILVA et. al., 2006)

Gomes et al. (2009) destacam, por sua vez, que os problemas complexos são comuns a uma infinidade de áreas e estão presentes em várias atividades públicas e privadas. Um dos problemas de decisão caracteriza-se pela disposição de um agente de decisão (indivíduo ou grupo de indivíduos a quem cabe a decisão) em exercer livremente uma escolha entre diversas possibilidades de ação, denominadas de alternativas, de forma que aquela considerada a mais satisfatória seja selecionada.

Gomes et. al. (2004) dizem que o analista de decisão é a pessoa encarregada de modelar o problema e, eventualmente, fazer as recomendações relativas à seleção final; e do tomador ou agente de decisão que, segundo esses autores, é o indivíduo ou grupo de indivíduos que, direta ou indiretamente, proporciona o juízo de valor final que poderá ser usado no momento de avaliar as alternativas disponíveis, com o objetivo de identificar a melhor escolha.

Em sua dimensão mais básica, um processo de tomada de decisão pode conceber-se como eleição por parte de um centro decisor (um indivíduo ou um grupo de indivíduos) da melhor alternativa entre as possíveis. O problema analítico está em definir o melhor e o possível em um processo de decisão. (ROMERO, 1996 apud GOMES et. al., 2009, p. 1) 
Tomar decisões complexas é, de modo geral, uma das mais difíceis tarefas enfrentadas individualmente ou por grupos de indivíduos, pois quase sempre tais decisões devem atender a múltiplos objetivos e, frequentemente, seus impactos não podem ser corretamente identificados.

Notadamente nesse processo de decisão, existem decisores que influenciam no processo de acordo com o juízo de valor intrínseco de casa um (relações intrínsecas que influenciam a decisão), sua cultura, o seu background, sua capacidade de articulação e seu dinamismo, visto que tais relações poderão ser modificadas durante o processo decisório a partir do enriquecimento de informações e/ou interferência de facilitadores.

A teoria da decisão não é uma teoria descritiva ou explicativa, já que não faz parte de seus objetivos descrever ou explicar como e/ou por que certas decisões. Pelo contrário, trata-se de uma teoria ora prescritiva ora normativa, no sentido de pretender ajudar as pessoas a tomarem decisões melhores, em face de suas preferências básicas. Essa teoria parte do pressuposto de que os indivíduos são capazes de expressar suas preferências básicas e são racionais, quando enfrentam situações de decisão simples. Com base nessa proposição, a metodologia desenvolvida pela teoria da decisão permite a resolução de problemas de decisão mais complexos. (GOMES et. al., 2009, p.21)

Iudícibus (2004) coloca algo interessante em relação ao processo de decisão relacionado ao background do usuário da informação, tendo em vista que precisa conhecer suficientemente bem para entender e interpretar as mutações ocorridas em relação ao processo gerencial de maneira que possa subsidiar o processo decisório.

Assim, podemos entender a tomada de decisão como o processo de identificar um problema ou uma oportunidade e selecionar uma linha de ação para resolvê-lo. Um problema ocorre quando o estado atual de uma situação é diferente do estado desejado. Uma oportunidade ocorre quando as circunstâncias oferecem a chance do indivíduo/organização ultrapassar seus objetivos e/ou metas. (LACHTERMACHER, 2002, p. 4).

Lachtermacher (2002, p. 4) destaca, dentre vários fatores, alguns que podem afetar a tomada de decisão, que sejam: O tempo disponível para a tomada de decisão; A importância da decisão; O ambiente; Certeza/incerteza e risco; Agentes decisores; e Conflitos de interesses. 
O autor classifica a tomada de decisão, segundo diversas formas, entre elas: a) Nível hierárquico: Estratégico; Gerencial; e Operacional. b) Tipo de informação disponível: Estruturada; Semiestruturada; Nãoestruturada. c) Quanto aos números de decisores: Decisão individual; e Decisão em grupo.

Já Gomes et al. (2009) classifica a decisão em dois tipos: 1) Intuitiva que se baseia nos conhecimentos previamente adquiridos; e 2) Analítica que utiliza a aplicação de métodos quantitativos.

Fica evidente, segundo os estudiosos, que as decisões individuais são menos complexas de serem tomadas. Para eles, o que pode dificultar um processo de tomada de decisão em grupo pode estar ligado às diferenças culturais entre os integrantes do grupo, bem como, a existência de situações de conflito entre os integrantes do processo de tomada de decisão. Reforçam ainda afirmando que a questão da comunicação, dependendo de sua clareza e objetividade, pode se transformar em complicador ou facilitador do processo.

\section{Gestão participativa de recursos hídricos}

Após mais de uma década de evoluções, o país chegou ao final dos anos 90 com um dos arcabouços legais de gestão da água mais modernos do mundo, processo esse coroado pela Lei 9.433/97 (Constituição Federal de 1997), que estabeleceu a Política Nacional de Recursos Hídricos e o SNGRH (Sistema Nacional de Recursos Hídricos). Essa modernização legal e institucional reformou o sistema de gestão da água no país e beneficiou-se da combinação de uma crise setorial de tensões macroeconômicas e de importantes mudanças do poder político nos anos 80. (MAGALHÃES JÜNIOR, 2010)

Notadamente, a Lei 9.433/97 traz a gestão integrada e participativa no art. $1^{\circ}$, inciso VI no qual, a gestão dos recursos hídricos deve ser descentralizada e contar com a participação do Poder Público, dos usuários e das comunidades.

Nesse contexto, a questão da participação dos atores sociais na gestão dos recursos naturais renováveis tem assumido importante papel nas relações sociedade-natureza, principalmente devido à omissão, ou então à sua fragilidade, dos modelos tradicionais de gestão fortemente presentes no contexto dessa relação, fato este que faz com que determinados sistemas de indicadores de sustentabilidade deixem de incluir em 
seus processos de escolha das variáveis chaves a participação dos atores locais dentro de todos os estágios das discussões, com a finalidade de se identificar as reais necessidades e a satisfação das aspirações de cada sociedade, através da identificação de políticas sustentáveis e estratégias de desenvolvimento.

Vieira e Weber (2002) mostram que as modalidades de desenvolvimento predominantes no atual contexto das relações sociedade-natureza não estariam favorecendo uma internalização efetiva das várias dimensões do "meio ambiente", demonstrando a fragilidade de aglutinar as várias facetas em um argumento explicativo complexo, capaz de permitir a identificação dos fatores condicionantes da complexidade ambiental.

O peso das variáveis socioculturais e político-institucionais nos processos de tomada de decisão sobre alternativas de desenvolvimento são fortemente orientadas pelo princípio da endogeneidade - dificultando a inserção de outras dimensões (VIEIRA; WEBER, 2002). Para estes autores, a gestão dos recursos naturais emerge como um dos componentes essenciais do processo de regulação das inter-relações entre os sistemas socioculturais e o meio ambiente biofísico, num horizonte que leva em conta a diversidade de representações cognitivas dos atores sociais em jogo, a variabilidade envolvida nas diferentes escalas espaciais (do local ao global) e temporais (do curto ao longo prazo), bem como as incertezas e controvérsias científicas que marcam a busca de compreensão dinâmica evolutiva dos sistemas socioambientais contemporâneos.

Nesse sentido, os novos desafios postos pelos autores num contexto de delimitação e estruturação progressivas de um campo integrado de pesquisas sobre meio ambiente, exigem um esforço sempre renovado de reconstrução de categorias básicas de análises, capaz de dotar a "problemática ambiental” dentro de um estatuto epistemológico cada vez mais nítido e consistente, facilitando, assim, tanto a comunicação nas práticas de integração interdisciplinar, quanto no próprio processo de formação de novas gerações de docentes e pesquisadores (VIEIRA; WEBER, 2002; GODARD, 2002).

Para Farias (2009), a realidade tem mostrado que é praticamente impossível que o Poder Público consiga acabar ou diminuir a degradação ambiental sem a participação da sociedade civil. Essa afirmação demonstra e corrobora o que Cândido et. al. (2010) dizem em relação à participação dos atores locais, que passou a ser necessária em todos 
os estágios das discussões, com a finalidade de se identificar as reais necessidades e a satisfação das aspirações de cada sociedade, através da identificação de políticas sustentáveis e estratégias de desenvolvimento.

Assim, Ollagnon (2002, p. 171), dentro do contexto da gestão integrada e participativa argumenta que:

Um novo tipo de gestão da natureza conclama à participação de novos tipos de gestores e à criação de novas maneiras de gestão." Para o autor, as sociedades industrializadas e urbanizadas interessadas em se adaptar a este padrão terão necessidade de gestores tradicionais. Mas estes só poderão agir em sintonia com o resto da sociedade. Em diferentes graus, todos os atores da sociedade deverão se constituir em "gestores da qualidade da natureza", na medida em que todos eles influenciam mais ou menos a qualidade desta. (OLLAGNON, 2002, p. 171).

$\mathrm{Na}$ visão de Berkes (2005), para que o uso de um determinado recurso comum seja considerado sustentável, deveria haver um feedback informando a instituição de gestão sobre o estado do recurso, e, da mesma forma, seria necessário dispor de um feedback entre o regime de gestão e o usuário do recurso.

Godard (2002) não acredita em uma gestão patrimonial dos recursos naturais integrada, sugere a alternativa da gestão patrimonial negociada capaz de representar uma figura de compromisso pela qual se busca estabelecer um novo princípio de legitimidade no espaço público.

Especificamente na gestão dos recursos hídricos, todos esses entendimentos são perfeitamente aplicáveis visto que é um cenário no qual o processo de tomada de decisões e de escolha de indicadores hidroambientais deve envolver vários agentes e múltiplos usos das águas, sendo, portanto, necessário ponderar os aspectos institucionais, políticos, sociais, econômicos, financeiros, hidrológicos, ambientais, culturais e dentre outros.

A degradação da qualidade da água e sua escassez qualitativa e quantitativa estão atualmente entre os principais focos de atenção das políticas ambientais em nível global. Os modelos de desenvolvimento baseados na utilização irracional dos recursos naturais motivaram reações e a busca de soluções visando à compatibilização entre exploração 
econômica e utilização racional dos estoques ambientais. A partir dos anos 80 , as iniciativas de modernização dos modelos e sistemas nacionais de gestão de água aproveitaram-se, então, do movimento global de busca da sustentabilidade. Nessas circunstâncias, a gestão ambiental e da água tiveram sua importância reforçada nas políticas públicas de desenvolvimento de numerosos países. (MAGALHÃES JUNIOR, 2010, p. 65).

Para o autor, este processo de valorização e modernização da gestão da água em países como o Brasil permitiu e exigiu, entretanto, um maior envolvimento e participação da sociedade, fato que levou à soma de esforços para a conscientização social e à abertura aos princípios de gestão descentralizada e participativa.

No Brasil, algumas iniciativas do governo federal, de determinados estados e de comitês de bacias, além de projetos de restauração de rios financiados por instituições privadas de grande porte, têm demonstrado a necessidade de engajar a população local nas ações de planejamento e de execução. Contudo, nessas iniciativas, não tem sido destacada a capacitação social como uma estratégia clara e sistemática para alcançar resultados positivos nas ações coletivas de suas localidades. (LIMEIRA et al., 2010, p. 18).

Para Magalhães Júnior (2010), um dos princípios mais valorizados nas modernas abordagens de gestão da água é da adoção da bacia hidrográfica como unidade principal de planejamento e gestão. A partir da escolha de uma unidade territorial adequada, a gestão da água deve ser incorporada em um processo mais amplo de gestão ambiental integrada, compreendida como a gestão de abordagem ecossistêmica; na qual, o desafio é realizar a transição demográfica, econômica, social e ambiental rumo a um equilíbrio durável diferentemente de uma gestão tradicional.

Todavia, Machado (2007, p. 1-2) argumenta que:

Apesar dos inegáveis avanços, ainda estamos longe de uma condição adequada em termos de gestão dos recursos hídricos no Brasil. Parcela significativa dos comitês de bacia ainda funciona precariamente, mantendo-se de pé, via-de-regra, graças a algum apoio governamental e, sobretudo, à consciência cidadã de abnegados. Apesar da reconhecida competência técnica e institucional, a Agência Nacional 
de Águas, entidade federal de implementação da Política Nacional de Recursos Hídricos e de coordenação do Sistema Nacional de Gerenciamento de Recursos Hídricos (SINGREH), ainda necessita de melhores condições para bem cumprir a sua relevante missão no timing adequado às necessidades do país, limitada que está pelos estreitos limites orçamentários e pelo seu insuficiente quadro técnico. (MACHADO, 2007, p.1-2).

O autor acrescenta que na maioria dos estados da federação, por outro lado, essas condições são ainda mais desfavoráveis e, apesar de todos eles terem concretizado a aprovação de suas leis de recursos hídricos, o que revela, sem dúvida, um esforço louvável, muitas das leis ainda estão numa fase incipiente de implementação e faltam recursos até para a estruturação mínima dos órgãos gestores de recursos hídricos.

Verifica-se conforme o entendimento do estudioso que essa situação, nos estados, é explicável e, até certo ponto, compreensível, dadas as condições econômicas adversas e de desequilíbrio fiscal em que muitos deles se encontram e o fato de estarem confrontados com outras urgências sociais no seu quotidiano. Porém, é certo que vacilações e retrocessos na implementação da política de recursos hídricos decorrem também, não raro, da falta de vontade política dos governantes, a qual parece ser explicada, na maioria dos casos, pela falta de percepção sobre a relevância estratégica de uma política de recursos hídricos.

De acordo com Limeira et al. (2010, p. 17), um desafio-chave na gestão de recursos naturais, em geral, consiste em continuar a construir e reforçar a abordagem de abrangência nacional, de programas para permanecerem receptivos às prioridades comunitárias em diferentes regiões geográficas e socioculturais. Não menos importante é encorajar uma ampla representação dos membros de organizações governamentais e de organizações não governamentais, dos meios científicos, dos estabelecimentos de ensino superior, de associações e mesmo a inserção de indivíduos, criando-se assim ocasiões indispensáveis para a troca de ideias, exposição de pontos de vista, propostas e conclusões.

Baseando-se nessa assertiva, é necessário transformar o modelo de funcionamento das ações ambientais no país, procurando fortalecer sua capacidade de gestão e aperfeiçoar a responsabilidade e a informação em relação às tomadas de decisões, considerando a complexidade crescente e a urgência de problemas ambientais, o compartilhar da governança e a 
transparência exigida cada vez mais pela população. Este fortalecimento ajudaria às instituições governamentais de gestão ambiental a oferecer melhores serviços à população, melhores e inovadoras adaptações, manter um diálogo mais rico com a população e aperfeiçoar os resultados, visando a melhoria do meio ambiente. (LIMEIRA et al., 2010, p. 17).

Do exposto, pode-se perceber que os princípios de gestão integrada e participativa dos Recursos Hídricos podem contribuir sobremaneira na busca de novos instrumentos de gestão visando a alcançar resultados mais favoráveis no longo prazo.

Colocar o tema da gestão integrada de recursos hídricos, no topo da agenda nacional, é, sem dúvida, o maior nó crítico a ser enfrentado no âmbito da Política Nacional de Recursos Hídricos, pois se assim não for, torna-se problemática a sua evolução no ritmo adequado às necessidades estratégicas do país (MACHADO, 2007).

Acrescente-se ainda a composição dos Comitês que tem sido objeto de diversos questionamentos, sobretudo, pela imprecisão do conceito "participação". Na última década, o termo "abordagem participativa" passou a fazer parte dos discursos governamentais, de ONGs e de diferentes agências internacionais de desenvolvimento. A interveniência de fatores não apenas técnicos, mas também de caráter político, econômico e cultural, torna o processo muito mais complexo, e o estilo de gestão que tende a prevalecer obedece a uma lógica sociotécnica. As relações de poder não desaparecem, mas passam a ser trabalhadas e negociadas conjuntamente entre leigos e peritos. Assim, a gestão colegiada tende a definir uma dinâmica que permite que os atores integrem e ajustem suas práticas tendo como base uma lógica de negociação sociotécnica que substitui uma concepção tecnocrática visando a ajustar interesses e propostas nem sempre convergentes e articulados para um objetivo comum. (JACOBI, 2005, p. 3).

Richter et al. (2003 apud LIMEIRA, 2008, p. 37-38) propõem uma estrutura para se iniciar um programa de gestão ecologicamente sustentável das águas, inserindo-se uma etapa da gestão adaptativa, já sendo experimentada em alguns países. Para eles, essa gestão é um processo interativo no qual, ambas as demandas, humanas e ecossistêmicas, são definidas, redefinidas, e modificadas para encontrar a sustentabilidade agora e no futuro, mais do que uma simples solução em determinado tempo. E isso requer um compromisso de todas as partes para uma participação contínua dentro de um dinâmico diálogo. 
A figura abaixo mostra um modelo de gestão adaptativa de gestão ecologicamente sustentável da água.

Figura 1 - Uma estrutura de gestão ecologicamente sustentável da água.

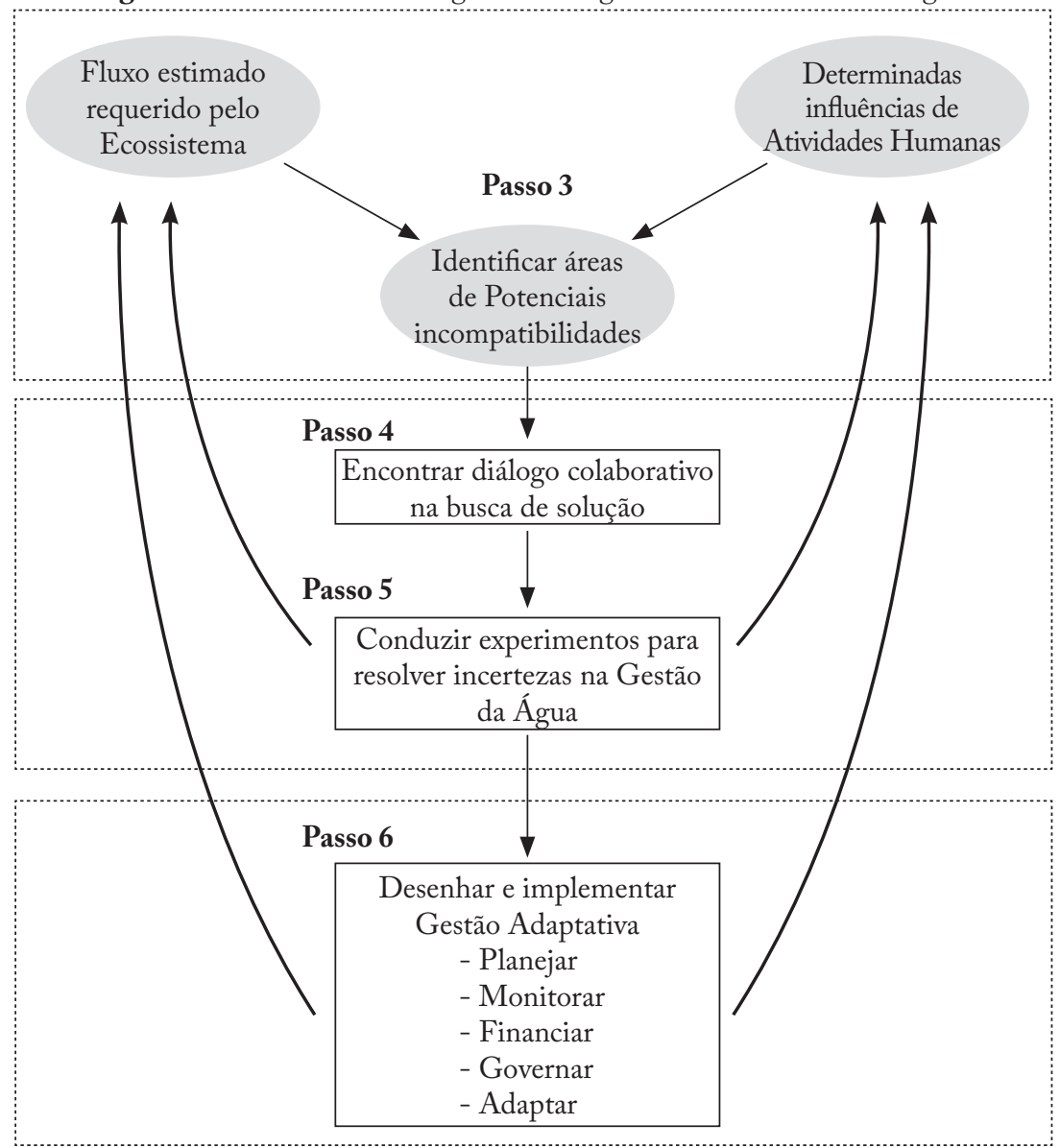

Fonte: Richter et al. (2003 apud LIMEIRA, 2008).

Essa proposta metodológica envolve a definição do problema, a partir da identificação de áreas de potenciais conflitos, seguido da busca pela solução da problemática a partir do diálogo colaborativo na resolução de incertezas na gestão da água e finalmente a gestão adaptativa que busca redesenhar e implementar o contexto da gestão.

A gestão adaptativa, segundo os autores, deve sempre começar com a definição de objetivos mutuamente aceitáveis para a gestão dos recursos hídricos. Essa definição relaciona-se com a saúde do ecossistema, benefícios econômicos e outras necessidades ou preferências sociais 
produzidas no passo quatro. Isto deve requerer numerosas iterações ou tentativas, tais como fazer modificações nas regras da operação da barragem ou nas programações de retirada da água. Isto também tornará necessário revisar os acordos mutuamente estabelecidos se todo o conjunto não puder ser realmente atendido. (LIMEIRA, 2008).

Todavia, percebe-se que essa metodologia, assim como outras relacionadas à gestão de recursos naturais, é de difícil aplicação, principalmente por envolver vários tomadores de decisão, indicadores e vários critérios e conflitos, visto que, no processo de decisão, toda decisão envolve vários elementos, como por exemplo: tomador de decisão, objetivos, preferências, estratégia, situação e resultado, sem falar que aspectos relacionados ao meio ambiente são extremamente complicados, posto estarem relacionados a várias dimensões (social, ambiental, econômica, institucional, dentre outras).

Para subsidiar o entendimento da participação de atores sociais na construção de indicadores hidroambientais, a seguir, estão descritos alguns aspectos relevantes que devem ser levados em consideração na escolha e construção.

\section{Processo de construção participativa dos indicadores de Hidroambientais}

Dentro do processo de decisão, em geral, são estabelecidos conflitos de interesse a partir das visões distintas dos decisores quer sejam econômicas, sociais, políticas, ambientais etc. Dessa forma, e por serem pessoas diferentes, é ao menos razoável aceitar que suas habilidades são desenvolvidas de maneira diferente e com comportamentos desiguais. Nesse sentido, a construção participativa dos indicadores de sustentabilidade a partir dos métodos da análise multicriterial e multivariada pode proporcionar o tratamento simultâneo de vários aspectos, levando em consideração metas, objetivos e atributos de cada indivíduo inserido dentro do processo decisório.

Sendo assim, a abordagem da análise multicritério e multivariada, na construção de indicadores, pode ser embasada nas colocações de Weber (2002), Jollivet e Pavé (2002) quando demonstram a importância da modelagem principalmente por dois motivos principais: pela natureza dos problemas a serem considerados (extremamente complexos, com várias dimensões envolvidas); e pela multiplicidade dos campos de especialização disciplinar envolvidos. 
De acordo com Lucena (1999, p. 2), as decisões nos diversos setores da sociedade vêm sendo tomadas tradicionalmente com base em apenas um ou dois critérios, geralmente o econômico e/ou financeiro, através de técnicas monocriteriais como, por exemplo, as de otimização da pesquisa operacional. Nestes tipos de métodos, não é simples levar em consideração a presença e a importância de fatores subjetivos, sejam eles quantificáveis ou não, conduzindo muitas vezes à escolha de uma alternativa que não seria a mais adequada para atender as prioridades socioeconômicas essenciais de uma comunidade.

Entende-se que um dos principais ingredientes da atividade econômica é a informação, e atualmente está bastante difundido o seu valor como recurso social e organizacional (SILVA, et al. 2006). Para esses autores, ao citarem Naisbitt (1982), a sociedade está vivendo o tempo dos parênteses, o tempo das eras. Esse tempo dos parênteses ocorre quando a sociedade se move de uma era industrial, centralizada, para uma era em que o uso da informação se torna chave para o sucesso. A partir de tais necessidades e exigências crescentes, o pensamento multicriterial e multivariado de tomada de decisão começou acrescer e tomar forma.

Para Pompermayer (2003, p.2), muito se sabe a respeito de ações potenciais de conservação dos recursos naturais, principalmente, daqueles em crescente escassez. No entanto, pouco se tem feito no sentido de evitar, num futuro próximo, sérios problemas diante das limitações desses recursos, particularmente os de natureza hídrica. Sendo assim, todo e qualquer esforço direcionado à recuperação, conservação e preservação dos recursos hídricos deve ser avaliado, para dar continuidade ao desenvolvimento econômico de forma sustentável, assegurando o bem-estar da humanidade.

Para a autora, várias são as ferramentas e métodos utilizados no campo do planejamento e gestão de recursos hídricos, como instrumentos de suporte à tomada de decisão, orientadas para a gestão contínua e integrada e o uso racional desses recursos. Vários são, também, os atores e agentes que, de uma forma ou de outra, estão envolvidos nessa questão e que atuam no processo de decisão, uma vez que a utilização de recursos hídricos envolve interesses múltiplos e, às vezes, conflitantes. (POMPERMAYER, 2003).

Notadamente a problemática da tomada de decisão nos dias atuais é caracterizada por um número crescente de alternativas e critérios conflitantes; dentre os quais, os decisores necessitam selecionar, ordenar, 
classificar ou ainda descrever com detalhes as alternativas a serem selecionadas, considerando múltiplos critérios. Em função dessa complexidade, a metodologia do Multicritério de Apoio à Decisão objetiva fornecer a quem necessita tomar uma decisão as ferramentas necessárias e suficientes para habilitá-lo nas soluções de problemas em que vários pontos de vista, até mesmo contraditórios, devem ser levados em consideração (ARAÚJO; ALMEIDA, 2009).

Braga e Gobetti (2002, p.361) destacam que, raramente, uma decisão é tomada em função de um único objetivo. Mesmo em problemas corriqueiros do dia a dia, como a compra de um equipamento doméstico de informática, em geral não utilizamos puramente o critério de mínimo custo. Outros fatores pesam na decisão: durabilidade do produto, garantia de manutenção etc. Para esses autores, o processo decisório envolve múltiplos objetivos e múltiplos decisores com visões diferenciadas acerca das metas a serem adotadas no planejamento e na gestão.

A fim de lidar com os problemas que envolvem vários objetivos simultaneamente, de uma maneira lógica, os métodos multicriteriais (MCDA) procuram ir ao encontro de uma perspectiva holística, agregando toda a informação disponível, incluindo o de natureza subjetiva. $\mathrm{O}$ objetivo é alcançar uma maior transparência e sistematização do processo decisório. (RANGEL et. al,. 2009, p. 579, tradução livre). ${ }^{2}$

Os métodos multicritérios visam a apoiar o processo decisório (não necessariamente prover uma solução). Curi e Curi (2010) argumentam que os objetivos da análise multicriterial concentram-se basicamente em estruturar o problema e no processo de escolha entre duas ou mais alternativas de decisão. $\mathrm{Na}$ estruturação do problema, os maiores desafios estão na representação e organização formalizada do problema para aprendizagem, investigação/análise, discussão e busca da solução. Por sua vez, na escolha entre duas ou mais alternativas, surgem alguns problemas, por exemplo: levam-se em consideração diferentes critérios (consequências); podem ser contraditórios; podem existir vários decisores e diferentes opiniões; incorporam-se os juízos de valores dos decisores; a solução pode não satisfazer a todos decisores; usam-se dados qualitativos ou quantitativos (até com diferentes ordens de grandeza); pode-se ter mais de uma "solução ótima".

2 In order to deal with problems which involve various objectives simultaneously in a logical way, MCDA methods seek to go deeper along a holistic outlook, aggregating all the information available including that of a subjective nature. 
Figura 2 - Processo Decisório da Análise Multicriterial

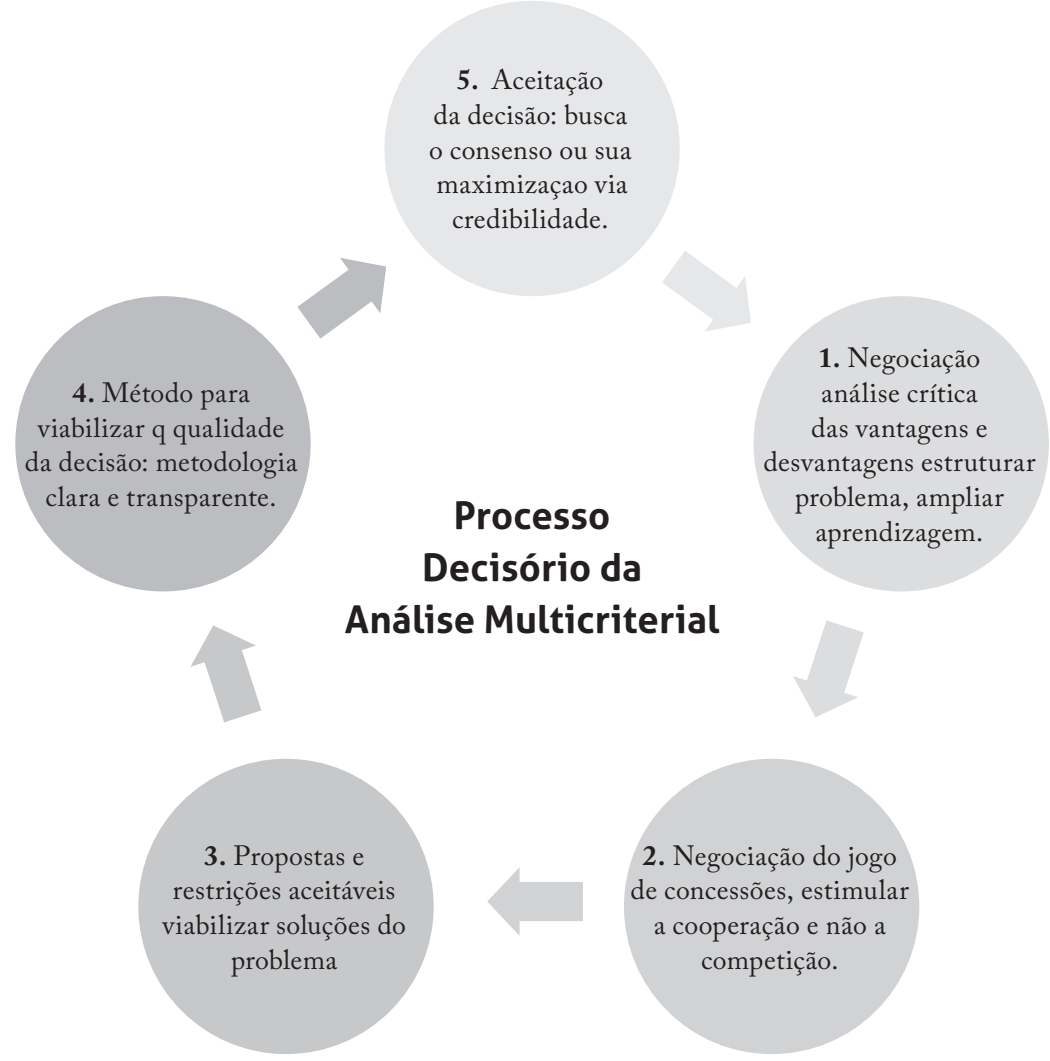

Fonte: Adaptado de Curi e Curi (2010)

Nesse sentido, o que se pode perceber, após tais entendimentos, é que o processo de construção participativa de indicadores hidroambientais de sustentabilidade pode levar em consideração o uso dessas técnicas multivariadas, posto serem contextos nos quais envolvem múltiplos usuários e múltiplas variáveis o que o torna algo complexo e de difícil resolução, visto que a tentativa de resolver problema(s), a partir de objetivos conflitantes e com vários entendimentos, pode acarretar uma abrangência diversa.

O uso de tais técnicas, na construção desse cenário, pode ser visualizado na figura abaixo, conforme o entendimento de Curi e Curi (2010). 
Figura 3 - Passos para a Análise Multicriterial.

\section{ANÁLISE MULTICRITERIAL E MULTIVARIADA}

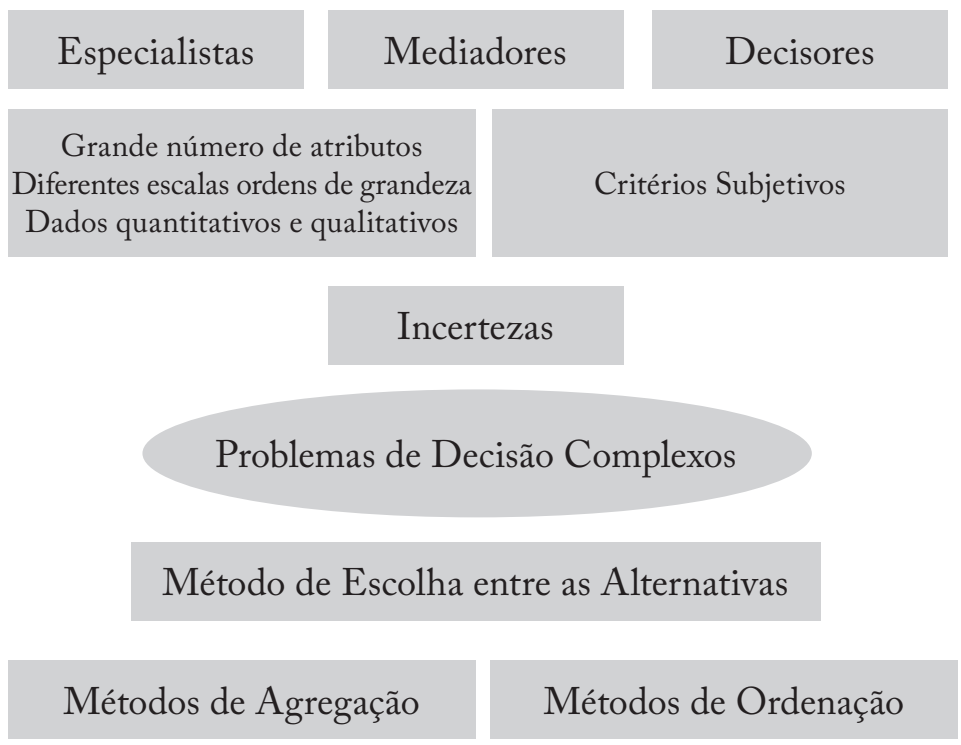

Fonte: Curi e Curi (2010)

$\mathrm{Na}$ área de recursos hídricos, os decisores ligados ao desenvolvimento econômico puro e simples, entendem que a melhor decisão refere-se à maximização do benefício econômico líquido uma vez que os valores econômicos expressam o interesse da sociedade. Por outro lado, os grupos ambientalistas radicais pregam a preservação do meio ambiente em sua forma natural e se opõem a qualquer intervenção que venha transformá-lo. Observa-se, portanto que existe entre estas duas posições extremadas um conjunto de possibilidades para se tentar soluções de compromisso. (BRAGA; GOBETTI, 2002).

Rotineiramente, tanto em nossa vida profissional como privada, deparamo-nos com problemas cuja resolução implica o que consideramos uma tomada de decisão complexa. De modo geral, tais problemas possuem pelo menos algumas das seguintes características:

- os critérios de resolução do problema são em número de, pelo menos, dois e conflitam entre si;

- tanto os critérios como as alternativas de solução não são claramente definidos e as consequências da escolha de dada alternativa com 
relação a pelo menos um critério não são claramente compreendidas;

- os critérios e as alternativas podem estar interligados, de tal forma que um critério parece refletir parcialmente outro critério, ao passo que a eficácia da escolha de uma alternativa depende de outra alternativa ter sido ou não também escolhida, no caso em que as alternativas não são mutuamente exclusivas;

- a solução do problema depende de um conjunto de pessoas, cada uma das quais tem seu próprio ponto de vista, muitas vezes conflitantes com os demais;

- as restrições do problema não são bem definidas, podendo mesmo haver alguma dúvida a respeito do que é critério e do que é restrição;

- alguns critérios são quantificáveis, ao passo que outros só o são por meio de julgamentos de valor efetuados sobre uma escala;

- a escala para dado critério pode ser cardinal, verbal ou ordinal, dependendo dos dados disponíveis e da própria natureza dos critérios;

- várias outras complicações podem surgir num problema real de tomada de decisão, mas esses sete aspectos anteriores caracterizam a complexidade de tal problema. Em geral, problemas dessa natureza são considerados mal estruturados. (GOMES et. al,. 2009).

Lyra (2008, p. 15) argumenta que o uso dos métodos multicritérios para apoio à decisão se baseia no princípio de que para a tomada de decisão, a experiência e o conhecimento são pelo menos tão valiosos quanto os dados utilizados. Estes métodos analisam problemas incorporando critérios, tanto quantitativos como qualitativos. É certo que o aumento da complexidade do processo de decisão na escolha de indicadores hidroambientais se dá através da quantidade de variáveis envolvidas, volume de informações, critérios estabelecidos etc., tudo isso dificulta a elaboração de presunções confiáveis e adequadas. Dessa forma, "[...] sem o uso de ferramentas quantitativas e qualitativas adequadas ter-se-á, naturalmente, a perda de precisão e de relevância nas informações pela limitação da capacidade humana de analisar todas as possíveis alternativas" (LYRA, 2008, p. 15). 
Dentro desse contexto, o uso da análise multivariada e da multicritério em recursos hídricos tem por finalidade auxiliar o processo de decisão. A literatura é vasta na exposição de aplicações dessas técnicas na área de recursos hídricos. Partindo dessa lógica, serão apresentados, de maneira conceitual, alguns aspectos interessantes sobre alguns métodos que podem subsidiar análises na construção de indicadores hidroambientais.

\section{Método Electre - Elimination and Et Choix Traduisant Realité}

O Método Electre (ELimination and $\boldsymbol{E}$ t Choix Traduisant $\boldsymbol{R}$ Ealité) aplica-se principalmente no tratamento de alternativas discretas avaliadas qualitativamente. (BRAGA; GOBETTI, 2002, p. 385). Todavia, verifica-se que pode ser utilizado também para variáveis contínuas, sob critérios quantitativos, ou para situações mistas. (JARDIM, 1999).

Uma das principais características introduzidas pelos métodos da família Electre corresponde a um novo conceito do modelo de preferências, que pretende ser uma representação mais realista que o utilizado na Teoria da Decisão.

Os Métodos Electre se caracterizam por utilizar o conceito francês súrclassente - traduzido para a língua inglesa como outranking e para a língua portuguesa como superação, subordinação, superclassificação, prevalência e, até mesmo, dominação. Segundo este conceito, uma alternativa genérica a - A domina uma outra alternativa genérica $\mathrm{b}-\mathrm{A}$ (aSb), se não existem argumentos suficientes para dizer que a é pior do que b. Como princípio, nestes métodos, consideram-se como dominadas as alternativas que "perdem" para as demais (ou são piores que as demais) em um maior número de critérios. (COSTA et. al., 2006).

A metodologia desenvolvida por Benayoun et al. (1966) e Roy (1968) sustenta-se nos três conceitos fundamentais: concordância, discordância e valores-limite, bem como utiliza um intervalo de escala no estabelecimento das relações-de-troca para a comparação das alternativas, aos pares. (JARDIM, 1999).

\section{Método AHP - Analytical Hierarchy Process}

Atualmente, tem-se presenciado um uso crescente da técnica de Estatística Multivariada chamada Método de Análise Hierárquica (SAATY, 1991), também conhecida como AHP - Analytical Hierarchy Process. 
De acordo com Carvalho e Mingoti (2005), este método se trata de uma ferramenta de auxílio a tomadas de decisão, que foi proposto recentemente por Thomas L. Saaty e visa a reproduzir o raciocínio humano no que diz respeito à comparação de elementos de um conjunto. Sendo assim, essa ferramenta auxilia na comparação de um conjunto de itens - que pode se tratar desde várias marcas de um produto como tênis, por exemplo, até um conjunto de diferentes tipos de investimentos - utilizando a opinião humana, ou seja, uma avaliação subjetiva. Para isso, ele usa uma escala de importância para confrontar os elementos dois a dois. A comparação se dá através de uma ordenação dos itens em questão de acordo com o nível de importância dos mesmos e dos seus respectivos atributos (características).

O método AHP, desenvolvido por Saaty (1980), consiste num conjunto de passos no qual todas as combinações de critérios organizadas em uma matriz são avaliadas em comparações par a par. A meta é determinar a importância relativa de cada alternativa em relação aos critérios selecionados para a avaliação. Devemos lembrar que estas importâncias serão determinadas pelas pessoas envolvidas no processo de decisão, ou seja, elas vão usar conhecimento próprio para fazer os julgamentos. Vale ressaltar que o método AHP tem a vantagem de permitir a comparação de critérios quantitativos e critérios qualitativos. (MORAES; SANTALIESTRA, 2007).

De acordo com Lyra (2008, p. 45), o AHP - Analytic Hierarquic Process é um método multicritério de escolha da melhor alternativa de decisão, com base na estruturação hierárquica e avaliação. Sua principal característica é a capacidade de analisar um problema considerando múltiplos critérios ou múltiplos objetivos. (LYRA, 2008, p. 45).

O AHP foi desenhado para refletir a maneira como as pessoas pensam, ou seja, identificando objetos e ideias e também as relações entre eles, com o objetivo de decompor a complexidade encontrada. Tem como base a representação de um problema complexo através de uma estruturação hierárquica. Essa estruturação consiste da definição do objetivo global e decomposição do sistema em vários níveis de hierarquia, o que possibilita a visualização do sistema como um todo e seus componentes. Possibilita, também, estudar as interações destes componentes e os impactos que os mesmos exercem sobre o sistema. (CAVASSIN, p. 24). 
Para a autora, não existe, na prática, um procedimento fixo para gerar os objetivos, critérios e alternativas e, assim, construir uma hierarquia. Isso dependerá dos objetivos escolhidos para decompor a complexidade daquele sistema. Os elementos que formam a hierarquia, previamente selecionados, devem ser organizados de maneira descendente, onde o objetivo principal deve estar no primeiro nível da hierarquia; os sub-objetivos, num nível abaixo; em seguida, os critérios e, finalmente, as alternativas.

Ao se deparar com um problema de comparação entre vários elementos de um conjunto, a mente humana cria um processo de hierarquização. Baseado nisso, a AHP é um método onde o problema analisado é estruturado hierarquicamente, sendo que no nível mais alto está o objetivo principal do estudo; nos níveis seguintes, estão os critérios (propriedades através das quais as alternativas serão avaliadas) e no nível mais baixo, estão as alternativas a serem decididas.(CARVALHO; MINGOTI, 2005).

O método AHP constitui-se dos seguintes passos: 1. Estruturar o problema de forma hierárquica, mostrando os elementos-chave e os relacionamentos entre critérios e alternativas; 2 . Organizar critérios e alternativas em matrizes para comparação par a par; 3. Comparar as alternativas de modo consistente, usando o conhecimento sobre o negócio, impressões e sensações que se tenha sobre o tema. Preferencialmente adequar a comparação à escala numérica elaborada por Saaty; 4. Calcular os pesos das alternativas e dos critérios dentro da hierarquia estabelecida; 5. Calcular a relação de consistência para avaliar se o julgamento feito pelo tomador de decisão é coerente e não levará a uma decisão equivocada; 6. Sumarizar os resultados e montar a escala final de valores com as alternativas ordenadas em ordem de preferência. (MORAES; SANTALIESTRA, 2007).

Curi e Curi (2010) mostram que a escolha das alternativas se dá seguindo as etapas: 1) Estruturação hierárquica; 2) Comparação paritária dos critérios por nível; 3) Princípio da priorização; 4) Sintetização das prioridades. Segundo os autores, o AHP tem uma estrutura simples; linguagem de fácil compreensão; serve para expressar a intuição e pensamento geral; os processos relacionados à decisão podem sofrer revisões de forma fácil; procura hierarquizar as alternativas em função das preferências do decisor; permite utilizar técnicas de análise de sistemas, ou seja, decompor cada critério em subcritérios e analisar as preferências do decisor de dentro para fora. Em relação a um de seus problemas, o autor diz que ao se retirar uma das alternativas, a ordem das demais pode mudar (criaram-se métodos alternativos). 


\section{Método PROMETHEE - Preference Ranking Method for Enrichment Evaluation}

A problemática da decisão multicritério pode ser modelada com o apoio de várias metodologias que avaliam e selecionam alternativas à luz de múltiplos critérios, muitas vezes conflitantes. (ARAÚ; ALMEIDA, 2009).

A literatura é rica em métodos multicritério para apoio à tomada de decisão. Entre estes, os métodos da família PROMETHEE (Preference Ranking Method for Enrichment Evaluation), que objetivam construir relações de sobreclassificação de valores em problemas de tomada de decisão. Brans, Vincke e Mareschal (1986) apresentaram o método PROMETHEE como uma nova classe de métodos de sobreclassificação em análise multicritério. Suas principais características são simplicidade, clareza e estabilidade. A noção de critério generalizado é usada para construir uma relação de sobreclassificação valorada. (ARAÚJO; ALMEIDA, 2009 apud VINCKE, 1992; BRANS, VINCKE; MARESCHAL, 1986).

No processo de análise, decompõe-se o objetivo em critérios e as comparações entre as alternativas são feitas no último nível de decomposição e aos pares, pelo estabelecimento de uma relação que acompanha as margens de preferência ditadas pelos agentes decisores (ARAÚJO; ALMEIDA, 2009 apud AL-RASHDAN et al., 1999).

Verifica-se, segundo os estudiosos, que o método PROMETHEE estabelece uma estrutura de preferência entre as alternativas discretas, tendo uma função de preferência entre as alternativas para cada critério. Essa função indica a intensidade da preferência de uma alternativa em relação à outra, com o valor variando entre 0 (indiferença) e 1 (preferência total).

Brans, Mareschal e Vincke (1986) consideram seis tipos de função de preferência (Método Promethee II), que são apresentadas na figura a seguir. No caso da função de preferência do tipo 1, existe indiferença entre duas alternativas $a$ e $b$, somente se $f(a)=f(b)$; se as avaliações forem diferentes, há preferência estrita pela alternativa de avaliação melhor. Neste caso, não há necessidade de definição de parâmetros. Na função do tipo 2, duas alternativas são indiferentes se a diferença entre suas avaliações não exceder o limiar de indiferença $q$; caso contrário, há preferência estrita (CAVASSIN, 2004). 
Para a função do tipo 3, é definido o limiar de preferência estrita $p$. Se a diferença entre avaliações de duas alternativas for menor que $p$, a preferência aumenta linearmente; se essa diferença for maior que $p$, existe preferência estrita pela alternativa de melhor avaliação. A função do tipo 4 utiliza os limiares de indiferença e preferência estrita, $p$ e $q$ respectivamente. Se $d(a, b)$ estiver entre $q$ e $p$, existe preferência fraca pela alternativa $a$; se $d(a, b)$ for menor que $q$, existe indiferença e se for maior que $p$, há preferência estrita pela alternativa a (CAVASSIN, 2004).

Figura 4 - Funções de Preferência - Promethee

Função Tipo 1

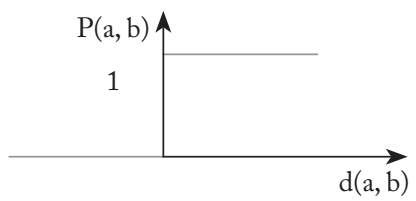

Função Tipo 3

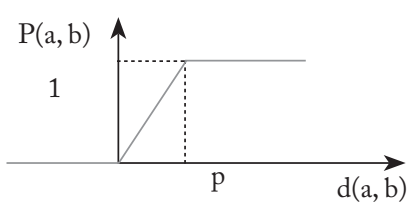

Função Tipo 5

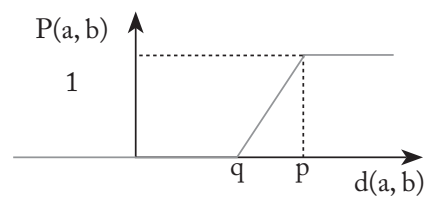

Função Tipo 2

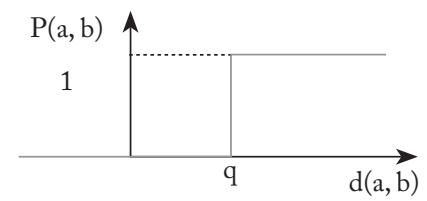

Função Tipo 4

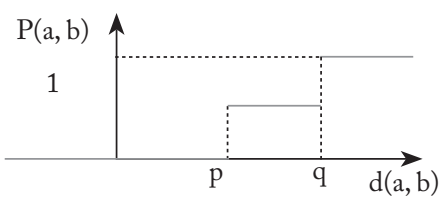

Função Tipo 6

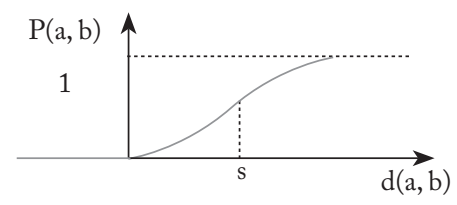

Fonte: Cavassin (2004)

Nesse método, o analista (considere o decisor ou o interessado no modelo) irá julgar alternativas em relação a cada critério de modo que seja capaz de montar uma matriz de preferência. A partir disso, analisará os fluxos positivos e negativos dos critérios nas alternativas obtendo assim a(s) melhor(es) alternativa(s) no processo de decisão. 


\section{Análise Multivariada: Análise Fatorial (AF)}

A Análise Fatorial (AF) é uma técnica estatística multivariada que possibilita ao pesquisador determinar a natureza de padrões nos quais, está envolvido um grande número de variáveis. Ela é particularmente útil nas pesquisas em que se tem por objetivo fazer uma "simplificação ordenada” do número de variáveis inter-relacionadas (SILVA et al, 2007).

O uso dessa técnica permite ao investigador reduzir os dados colhidos durante a pesquisa, com o intuito de sintetizá-los para melhor explicar o problema, sem comprometer a qualidade das informações.

Segundo Hair et al. (2005, p. 90 apud SOARES, 2006, p. 72), “[...] a análise fatorial pode ser utilizada para examinar os padrões ou relações latentes para um grande número de variáveis e determinar se a informação pode ser condensada ou resumida a um conjunto menor de fatores [...]". Para os autores, essa técnica analisa as correlações entre um grande número de variáveis, resumindo-as em grupos (fatores) de variáveis que mais se correlacionam.

Para se proceder com os testes da AF, Soares (2006) afirma que possui quatro etapas:

- Verificar a adequação da aplicação da AF;

- Extração dos fatores mais significativos que representarão os dados, por meio do método mais adequado;

- Aplicação de rotação nos fatores, para facilitar o entendimento deles;

- Geração dos scores fatoriais para utilização e outras análises, caso seja necessário.

Como etapa inicial para análise, observa-se o KMO - KaiserMeyer-Oklin ou MSA - Measure of Sampling Adequacy (Medida de Adequacidade da Amostra) que no entendimento de Hair et al. (2005) é um teste que permite avaliar quão adequada é a aplicação da AF, valores entre 0,5 e 1,0 para a matriz toda ou para uma variável individual indicam tal adequação.

O teste de esfericidade ou Bartlett's Test of Sphericity, na concepção de Soares (2006, p. 70), "testa se a matriz de correlação é igual à matriz identidade, e verifica se a correlação existente entre as variáveis é significativa [...]”. Souki e Pereira (2004) afirmam que quanto mais próximo de zero $(0,000)$ for o nível de significância (Sig.) do teste de esfericidade 
de Bartlett, maior será a adequação da AF para um conjunto de dados, caso o valor do Sig. ultrapasse 0,05 , inviabiliza a aplicação da AF.

A communalities ou comunalidade é a medida de quanto da variância de uma variável é explicada pelos fatores derivados pela AF. A comunalidade avalia a contribuição de uma variável original com todas as outras variáveis incluídas no modelo. Comunalidades menores que 0,50 não têm explicação suficiente, devendo o investigador ignorar a variável ou avaliá-la para possível eliminação. (HAIR et al., 2005, p. 90 apud SOARES, 2006).

O Principal Component Analysis a ACP-Análise dos Componentes Principais tem como objetivo "[...] resumir a informação presente nas variáveis originais (geralmente correlacionadas) num número reduzido de índices (componentes) ortogonais (não-correlacionados) que explicam o máximo possível de variância das variáveis originais [...]”. (MAROCO, 2003, p. 292 apud SOARES, 2006, p. 71). Dessa forma, recomenda-se que os componentes fatoriais expliquem, no mínimo, $60 \%$ da variância.

Quanto à aplicação de rotação nos fatores, na visão de Soares (2006), o método comumente usado é o processo varimax, que resulta em fatores ortogonais, para transformar a matriz de fatores em uma matriz mais simples e de fácil interpretação.

Finaliza-se a análise nomeando cada fator (componente) encontrado, a fim de identificar qual a relação existente entre as variáveis, para validação dos resultados da pesquisa.

No caso específico da construção dos indicadores de sustentabilidade hidroambiental, é perfeitamente viável aplicar a técnica. Tome-se como exemplo o caso de se investigar a percepção de determinado público-alvo acerca da importância dos indicadores hidroambientais. Os resultados obtidos podem subsidiar a construção de um índice hidroambiental capaz de contribuir na gestão dos recursos hídricos.

\section{Proposta de construção de indicadores hidroambientais}

Nesta seção, é apresentada uma descrição sucinta da proposta de construção de indicadores que foi elaborada a partir da literatura específica exposta neste recorte teórico, em especial do estudo de Magalhães Júnior (2010), Guimarães (2008), Vieira e Studart (2009). 
Quadro 1 - Proposta de Indicadores Hidroambientais para Bacias Hidrográficas

\begin{tabular}{|c|c|c|}
\hline & Indicador & Unidade \\
\hline \multirow{5}{*}{$\begin{array}{c}\text { Perda de } \\
\text { cobertura } \\
\text { Extinção de } \\
\text { Vegetais } \\
\text { Extensão dos } \\
\text { Rios }\end{array}$} & $\begin{array}{c}\text { Índice de perda de cobertura vegetal por } \\
\text { bioma }\end{array}$ & $\% / a n o$ \\
\hline & $\begin{array}{l}\text { Índice de cobertura vegetal natural e } \\
\text { plantada existente por bioma }\end{array}$ & \% de área \\
\hline & $\begin{array}{l}\text { Índice de substituição de cobertura vege- } \\
\text { tal natural por cobertura plantada }\end{array}$ & $\begin{array}{c}\text { \% de área por espécie por } \\
\text { ano }\end{array}$ \\
\hline & $\begin{array}{l}\text { Índice de riscos de extinção de vegetais } \\
\text { superiores }\end{array}$ & $\begin{array}{c}\text { No de espécies ameaçadas } \\
\text { de extinção por classe de } \\
\text { risco }\end{array}$ \\
\hline & $\begin{array}{c}\text { Extensão dos rios com matas ciliares em } \\
\text { conformidade legal }\end{array}$ & $\mathrm{Km} \mathrm{e} \%$ \\
\hline \multirow{2}{*}{$\begin{array}{l}\text { Erosão } \\
\text { Acelerada }\end{array}$} & $\begin{array}{c}\text { Índice de suscetibilidade do solo à erosão } \\
\text { acelerada }\end{array}$ & \% de área \\
\hline & $\begin{array}{c}\text { Densidade dos focos de erosão acelerada } \\
\text { (voçorocas) }\end{array}$ & $\mathrm{No} / \mathrm{km}^{2}$ \\
\hline \begin{tabular}{|c|} 
Ocorrência de \\
Eventos Críticos
\end{tabular} & $\begin{array}{c}\text { Probabilidade de ocorrência de secas, } \\
\text { estiagens e inundações }\end{array}$ & No de eventos/tempo \\
\hline Precipitação & Precipitação média anual & Milímetros (mm) \\
\hline Armazenamento & Índice de armazenamento de água & $\mathrm{M}^{3}$ reservado por ha/ano \\
\hline \multirow{7}{*}{$\begin{array}{l}\text { Demandas } \\
\text { Hídricas }\end{array}$} & $\begin{array}{c}\text { Índice de Confiabilidade Hídrica (Índice } \\
\text { de Hashimoto) }\end{array}$ & $\begin{array}{l}\text { Frequência de falhas do } \\
\text { sistema hídrico }\end{array}$ \\
\hline & $\begin{array}{l}\text { Índice de Resiliência } \\
\text { (Índice de Hashimoto) }\end{array}$ & $\begin{array}{c}\text { Como o sistema retorna } \\
\text { ao seu estado satisfatório } \\
\text { depois de uma falha }\end{array}$ \\
\hline & $\begin{array}{l}\text { Índice de Vulnerabilidade } \\
\text { (Índice de Hashimoto) }\end{array}$ & $\begin{array}{c}\text { Consequências que uma } \\
\text { falha pode provocar no } \\
\text { sistema }\end{array}$ \\
\hline & $\begin{array}{l}\text { Critério da sustentabilidade hídrica } \\
\text { (Índice de Hashimoto) }\end{array}$ & $\begin{array}{l}\text { Razão direta de aumentos } \\
\text { da confiabilidade e da } \\
\text { resiliência, e de decrés- } \\
\text { cimo da vulnerabilidade. }\end{array}$ \\
\hline & Vazões médias anuais & $\mathrm{m}^{3} / \mathrm{km}^{2}$ \\
\hline & $\begin{array}{l}\text { Vazões mínimas com dada duração e } \\
\text { dado período de recorrência }\end{array}$ & $\begin{array}{l}\mathrm{m}^{3} / \mathrm{s}, \text { dia, mês etc; valores } \\
\text { per capita. }\end{array}$ \\
\hline & Coeficiente de superávit hídrico total & $\begin{array}{c}\text { Disponibilidade hídrica/ } \\
\text { demandas hídricas de usos } \\
\text { diversos }\end{array}$ \\
\hline
\end{tabular}




\begin{tabular}{|c|c|c|}
\hline \multirow{2}{*}{$\begin{array}{l}\text { Demandas } \\
\text { Hídricas }\end{array}$} & Quantidade de poços d'água subterrâneos & $\begin{array}{c}\text { Quantidades (número de } \\
\text { poços) }\end{array}$ \\
\hline & $\begin{array}{c}\text { Vazões médias de bombeamento de águas } \\
\text { subterrâneas }\end{array}$ & $\mathrm{m}^{3} / \mathrm{km}^{2}$ ou $\mathrm{m}^{2} /$ habitantes \\
\hline \multirow{9}{*}{$\begin{array}{l}\text { Conformidade } \\
\text { Legal da Água } \\
\text { (em relação } \\
\text { aos usos ou } \\
\text { às classes de } \\
\text { enquadramento } \\
\text { - CONAMA e } \\
\text { Ministério da } \\
\text { Saúde) }\end{array}$} & $\begin{array}{l}\text { Taxa de conformidade em relação à } \\
\text { Turbidez }\end{array}$ & $\%$ de amostras \\
\hline & $\begin{array}{l}\text { Taxa de conformidade em relação aos } \\
\text { Sólidos Totais Dissolvidos (SDT) }\end{array}$ & $\%$ de amostras \\
\hline & $\begin{array}{l}\text { Taxa de conformidade em relação à DBO } \\
\text { - Demanda Bioquímica de Oxigênio }\end{array}$ & $\%$ de amostras \\
\hline & $\begin{array}{l}\text { Taxa de conformidade em relação ao } \\
\text { Oxigênio Dissolvido (OD) }\end{array}$ & $\%$ de amostras \\
\hline & $\begin{array}{l}\text { Taxa de conformidade em relação aos } \\
\text { metais pesados }\end{array}$ & $\begin{array}{c}\% \text { de amostras por tipo de } \\
\text { metal }\end{array}$ \\
\hline & $\begin{array}{c}\text { Taxa de conformidade em relação à taxa } \\
\text { de carbono orgânico }\end{array}$ & $\%$ de amostras \\
\hline & $\begin{array}{l}\text { Taxa de conformidade em relação aos } \\
\text { nitratos }\end{array}$ & $\%$ de amostras \\
\hline & $\begin{array}{l}\text { Destaque para a superpopulação de } \\
\text { macrófitas aquáticas (eutrofização) }\end{array}$ & $\%$ do valor ideal \\
\hline & IQA - Índice de Qualidade da Água & Média anual \\
\hline \multirow{8}{*}{$\begin{array}{c}\text { Pressões sobre } \\
\text { os estoques } \\
\text { hídricos } \\
\text { (quantidade e } \\
\text { qualidade) } \\
\text { Urbanização } \\
\text { Concentração } \\
\text { Populacional } \\
\text { Turismo } \\
\text { Atividades } \\
\text { Agrícolas }\end{array}$} & Índice de urbanização & $\begin{array}{c}\% \text { de área ou \% de área por } \\
\text { domínio hidrológico }\end{array}$ \\
\hline & $\begin{array}{c}\text { Índice de urbanização por tipo de domí- } \\
\text { nio hidrológico }\end{array}$ & $\begin{array}{l}\text { \% de área por domínio } \\
\text { hidrológico }\end{array}$ \\
\hline & Índice de impermeabilidade do solo & $\begin{array}{c}\% \text { de área } \\
\text { impermeabilizada }\end{array}$ \\
\hline & Coeficiente de escoamento superficial & $\%$ \\
\hline & $\begin{array}{c}\text { Densidade populacional total, urbana, } \\
\text { rural }\end{array}$ & $\mathrm{Hab} . / \mathrm{km}^{2}$ \\
\hline & Índice de pressão turística & No. de turistas $/ \mathrm{km}^{2}$ \\
\hline & Índice de áreas agrícolas & $\begin{array}{l}\% \text { de área ocupada por } \\
\text { tipo de uso }\end{array}$ \\
\hline & Índice de pressão da pecuária & No. de reses $/ \mathrm{km}^{2}$ \\
\hline
\end{tabular}




\begin{tabular}{|c|c|c|}
\hline \multirow{7}{*}{$\begin{array}{c}\text { Pressões sobre } \\
\text { os estoques } \\
\text { hídricos } \\
\text { (quantidade e } \\
\text { qualidade) } \\
\text { Urbanização } \\
\text { Concentração } \\
\text { Populacional } \\
\text { Turismo } \\
\text { Atividades } \\
\text { Agrícolas }\end{array}$} & $\begin{array}{l}\text { Índice de ocupação agrícola por tipo de } \\
\text { cultivo }\end{array}$ & \% de área \\
\hline & Índice de produção agrícola & Percapita/ano e por ha/ano \\
\hline & $\begin{array}{c}\text { Índice de captação de água por setor } \\
\text { usuário }\end{array}$ & \% dos estoques hídricos \\
\hline & $\begin{array}{l}\text { Índice de consumo médio por água for- } \\
\text { necida via rede geral }\end{array}$ & $\mathrm{m}^{3} /$ habitante servido \\
\hline & Índice de consumo dos estoques hídricos & $\% /$ ano \\
\hline & \begin{tabular}{|c|} 
Índice de captação de água para abasteci- \\
mento público urbano e rural \\
\end{tabular} & $\mathrm{m}^{3} /$ per capita \\
\hline & $\begin{array}{l}\text { Índice de captação de águas } \\
\text { superficiais e subterrâneas }\end{array}$ & $\%$ de estoques hídricos \\
\hline \multirow{3}{*}{$\begin{array}{l}\text { Demandas } \\
\text { Agrícolas }\end{array}$} & Índice de captação de água para irrigação & $\mathrm{M}^{3} /$ hectare (ha) \\
\hline & Índice de área irrigada & $\begin{array}{l}\% \text { do total ou da área } \\
\text { cultivada }\end{array}$ \\
\hline & $\begin{array}{l}\text { Índice de perdas de água na irrigação } \\
\text { Índice de rebanhos por tipo de criações }\end{array}$ & $\begin{array}{c}\% \text { do volume produzido ou } \\
\mathrm{m}^{3} / \mathrm{ha} / \mathrm{ano} \\
\text { No de cabeças } / \mathrm{km}^{2}\end{array}$ \\
\hline $\begin{array}{l}\text { Demandas } \\
\text { industriais }\end{array}$ & $\begin{array}{c}\text { Índice de captação de água para uso } \\
\text { industrial }\end{array}$ & $\begin{array}{c}\mathrm{m}^{3} / \text { ano e } \% \text { dos estoques } \\
\text { hídricos }\end{array}$ \\
\hline $\begin{array}{c}\text { Dependência } \\
\text { Hídrica Externa }\end{array}$ & $\begin{array}{c}\text { Índice de derivação de águas entre bacias } \\
\text { hidrográficas }\end{array}$ & $\begin{array}{c}\mathrm{m}^{3} / \text { ano e } \% \text { dos estoques } \\
\text { hídricos }\end{array}$ \\
\hline $\begin{array}{l}\text { Pressões } \\
\text { Agrícolas }\end{array}$ & $\begin{array}{c}\text { Índice de vendas ou de consumo de agro- } \\
\text { tóxicos e fertilizantes }\end{array}$ & $\begin{array}{l}\mathrm{Kg} / \mathrm{ha} \text { plantado; quanti- } \\
\text { dade em } \mathrm{kg}\end{array}$ \\
\hline $\begin{array}{c}\text { Pressões } \\
\text { Industriais }\end{array}$ & $\begin{array}{l}\text { Índice de indústrias com potencial } \\
\text { poluidor }\end{array}$ & $\%$; total de indústrias \\
\hline $\begin{array}{c}\text { Desempenho } \\
\text { do sistema de } \\
\text { gestão no setor } \\
\text { de saneamento } \\
\text { básico } \\
\end{array}$ & $\begin{array}{l}\text { Índice de satisfação social em relação ao } \\
\text { serviço }\end{array}$ & $\begin{array}{c}\% \text { da população satisfeita } \\
\text { ou não }\end{array}$ \\
\hline Satisfação social & $\begin{array}{l}\text { Tarifa média praticada por } \mathrm{m}^{3} \text { de esgoto } \\
\text { coletado ou tratado }\end{array}$ & $\mathrm{R} \$ / \mathrm{m}^{3}$ \\
\hline
\end{tabular}




\begin{tabular}{|c|c|c|}
\hline \multirow{4}{*}{$\begin{array}{l}\text { Ética financeira } \\
\text { Abastecimento } \\
\text { público de água }\end{array}$} & $\begin{array}{l}\text { Tarifa média praticada por } \mathrm{m}^{3} \text { de água } \\
\text { distribuído }\end{array}$ & $\mathrm{R} \$ / \mathrm{m}^{3}$ \\
\hline & $\begin{array}{l}\text { Índice de atendimento urbano de água } \\
\text { via rede geral }\end{array}$ & $\begin{array}{l}\text { \% população urbana e } \\
\text { rural }\end{array}$ \\
\hline & $\begin{array}{l}\text { Índice de atendimento de água por rede } \\
\text { geral, poços ou nascentes na propriedade }\end{array}$ & $\begin{array}{l}\text { \% população urbana e } \\
\text { rural }\end{array}$ \\
\hline & Índice de perdas de água na rede geral & $\begin{array}{l}\% \text { do volume produzido; } \\
\mathrm{m}^{3} / \mathrm{km} \text { de rede/ano }\end{array}$ \\
\hline $\begin{array}{l}\text { Coleta de } \\
\text { Esgotos }\end{array}$ & Índice de coleta de esgotos & $\begin{array}{l}\% \text { do volume de água } \\
\text { consumido }\end{array}$ \\
\hline \multirow{3}{*}{$\begin{array}{l}\text { Tratamento } \\
\text { de esgotos e } \\
\text { efluentes }\end{array}$} & Índice de tratamento de esgotos coletados & $\begin{array}{l}\% \text { de volume ou } \% \text { de } \\
\text { poluentes eliminados }\end{array}$ \\
\hline & $\begin{array}{l}\text { Índice de tratamento dos esgotos em } \\
\text { relação ao volume de água consumido }\end{array}$ & $\%$ por tipo de tratamento \\
\hline & $\begin{array}{l}\text { Índice de remoção de coliformes fecais } \\
\text { nas estações de tratamento de esgotos } \\
\text { (ETEs) }\end{array}$ & $\%$ \\
\hline \multirow{4}{*}{$\begin{array}{l}\text { Indicadores de } \\
\text { atendimento de } \\
\text { coleta de lixo }\end{array}$} & $\begin{array}{l}\text { Índice de população atendida por coleta } \\
\text { de lixo }\end{array}$ & $\%$ da população atendida \\
\hline & $\begin{array}{l}\text { Total de investimentos no setor de coleta } \\
\text { de lixo }\end{array}$ & Valor em $\mathrm{R} \$$ \\
\hline & No município existe aterro sanitário & Sim; Não \\
\hline & Indicador de coleta de lixo & $\begin{array}{l}\text { Total de lixo coletado } \\
\text { (toneladas) }\end{array}$ \\
\hline \multirow{7}{*}{$\begin{array}{c}\text { Desenvolvimento } \\
\text { Humano }\end{array}$} & IDH-M & $\begin{array}{c}\text { Índice de } \\
\text { Desenvolvimento } \\
\text { Humano Municipal }\end{array}$ \\
\hline & ICV (Índice de Condições de Vida) & 0 a 1 \\
\hline & Expectativa de Vida ao Nascer & n. ${ }^{\circ}$ de anos \\
\hline & Taxa de crescimento & $\% /$ ano \\
\hline & Índice de Mortalidade Infantil & $\begin{array}{l}\text { Óbitos em relação a } 1.000 \\
\text { nascidos vivos/ano }\end{array}$ \\
\hline & $\begin{array}{c}\text { Número de instituições com projetos de } \\
\text { educação ambiental }\end{array}$ & $\begin{array}{l}\text { Quantidade de cursos/ } \\
\text { instituições }\end{array}$ \\
\hline & $\begin{array}{l}\text { Taxa de redução do Índice de } \\
\text { Mortalidade Infantil }\end{array}$ & $\% /$ ano \\
\hline
\end{tabular}




\begin{tabular}{|c|c|c|}
\hline \multirow{4}{*}{$\begin{array}{c}\text { Desenvolvimento } \\
\text { Humano }\end{array}$} & Índice de Analfabetismo & $\% / a n o$ \\
\hline & Taxa de redução do Analfabetismo & $\% / a n o$ \\
\hline & Índice de Pobreza & $\%$ população total \\
\hline & $\begin{array}{l}\text { Taxa de crescimento do Índice de } \\
\text { Pobreza }\end{array}$ & $\% / a n o$ \\
\hline \multirow{4}{*}{ Saúde Pública } & $\begin{array}{l}\text { Índice de ocorrência de doenças por } \\
\text { transmissão hídrica }\end{array}$ & $\begin{array}{l}\text { n. }{ }^{\circ} \text { de casos confirmados a } \\
\text { cada } 100.000 \text { habitantes }\end{array}$ \\
\hline & $\begin{array}{c}\text { Óbitos por doenças de transmissão } \\
\text { hídrica }\end{array}$ & $\begin{array}{l}\text { No de casos / } 1.000 \\
\text { habitantes }\end{array}$ \\
\hline & No de médicos por 1.000 habitantes & Quantidade de médicos \\
\hline & Acesso á saúde & $\begin{array}{c}\text { No de habitantes por esta- } \\
\text { belecimento médico }\end{array}$ \\
\hline \multirow{7}{*}{$\begin{array}{l}\text { Indicadores } \\
\text { Institucionais } \\
\text { Indicadores } \\
\text { Institucionais }\end{array}$} & A bacia tem comitê de bacia? & $\mathrm{Sim} / \mathrm{Não}$ \\
\hline & A bacia hidrográfica tem órgão gestor? & Sim/Não \\
\hline & Município participa do comitê de bacia? & Sim/Não \\
\hline & A bacia tem plano de bacia? & Sim/Não \\
\hline & A bacia tem sistema de outorga? & Sim/Não \\
\hline & A bacia tem sistema de cobrança? & Sim/Não \\
\hline & Coleta seletiva de lixo & $\begin{array}{c}\text { Tonelada/dia; } \% \text { do lixo } \\
\text { total }\end{array}$ \\
\hline
\end{tabular}

Fonte: Adaptado de Magalhães Júnior (2010), Guimarães (2008), Vieira e Studart (2009).

Do exposto, pretende-se com tal proposta contar com a participação de especialistas da área, que tenham supostamente um conhecimento preliminar acerca dos indicadores. A ideia consistirá em apresentar uma proposta de indicadores hidroambientais para bacias hidrográficas, considerando os componentes de cada categoria/dimensão. Obviamente que se pretende contar com a participação dos atores envolvidos (especialistas da área) de modo que após a combinação dos indicadores mais importantes, seja capaz de aplicar os indicadores escolhidos como mais relevantes em um estudo de caso de uma bacia hidrográfica para ver a aplicabilidade do sistema de maneira que possa proporcionar informações compactas e objetivas para o gerenciamento dos recursos hídricos. 


\section{Considerações Finais}

É fato que ainda não existe um consenso teórico e tampouco empírico de qual modelo de sistemas de indicadores hidroambientais deve ser seguido, o certo é que novas propostas vêm sendo desenvolvidas e aplicadas em bacias hidrográficas.

Com o desenvolvimento de sistemas de indicadores hidroambientais, será possível confeccionar uma ferramenta capaz de fornecer informações sistematizadas e gerar mapeamentos para diversas unidades espaciais de consultas de modo a permitir um diagnóstico hidroambiental em bacias hidrográficas. Com base nessa discussão, a propositura de um sistema com essa natureza se constitui um instrumento versátil capaz de subsidiar o processo de decisão na área de recursos de maneira que possa contribuir para uma gestão participativa dos recursos hídricos.

Os assuntos expostos ensejam que o entendimento de uma construção participativa de indicadores hidroambientais pode certamente contribuir para a busca de um modelo de sistema de sustentabilidade hídrica capaz de minimizar as divergências existentes entre os indicadores definidos de maneira isolada sem a participação dos vários atores envolvidos.

Do exposto, espera-se que os desafios para a construção de indicadores hidroambientais sejam superados na medida em que essa questão, de fato, venha a ser tratada com maior consistência pelos vários atores sociais envolvidos de maneira que possam efetivamente refletir as necessidades que a área hídrica necessita. Um passo fundamental para isso é a compreensão efetiva da interdisciplinaridade, dos métodos de análise multivariada por parte desses atores, visto que, a partir desse entendimento, poderão surgir abordagens diferenciadas para cada grupo envolvido de acordo com suas características comuns de construção de cada área de atuação, em busca de uma maior eficiência das relações profissionais. Notadamente, que surjam novas medidas mais eficazes e condizentes como forma de enfrentar os problemas hidroambientais (sejam em estratégias de postura individual ou coletiva), no intuito de minimizar ou corrigir as deficiências existentes, fruto de uma postura de caráter fortemente disciplinar, em que cada disciplina ou área quer mostrar apenas seu "trabalho" sem discutir as relações entre outras áreas de conhecimento. 
Finalmente, conclui-se que a internalização da sistemática de indicadores de sustentabilidade hidroambiental, a partir de uma interação participativa, carece de muita discussão e de muito tempo para materializar-se dentro da gestão das águas principalmente se considerarmos que a complexidade e as questões paradoxais que permeiam o termo da sustentabilidade hídrica. Nesse sentido, mesmo com toda relevância que se possa obter na construção de um modelo dessa natureza, qualquer tentativa de medir essa sustentabilidade terá sempre muitas limitações. Sendo assim, por mais cuidados metodológicos na busca de consistência, dada a complexidade de cada um dos indicadores, variáveis e dimensões envolvidas e, principalmente, pela multiplicidade de possibilidades de inter-relações entre os indicadores considerados e, ainda, por outras razões diversas que um ou outro indicador não seja utilizado, os resultados serão sempre duvidosos e discutíveis. 


\section{Referências}

ARAÚJO, A. G. de; ALMEIDA, A. T. de. Apoio à decisão na seleção de investimentos em petróleo e gás: uma aplicação utilizando o método PROMETHEE. Revista Gest. Prod., São Carlos, v. 16, n. 4, p. 534-543, out.-dez. 2009.

BECK, C. G. et. al. Problemática dos Resíduos Sólidos Urbanos do Município de João Pessoa: Aplicação do Modelo P-E-R. Qualit@s Revista Eletrônica, Campina Grande, PB, v.8, n. 3, 2009.

BERKES, F. Sistemas sociais, Sistemas Ecológicos e Direitos de Apropriação de Recursos Naturais. In: VIEIRA, P. F.; BERKES, F.; SEIXAS, C. S. Gestão Integrada e Participativa de Recursos Naturais: Conceitos, métodos e experiências. Florianópolis: Secco/APED, 2005. Cap. 1.

BRAGA; B.; GOBETTI, L. Análise Multiobjetivo. In: PORTO, Rubem La Laina et al. (Org.) Técnicas Quantitativas para o Gerenciamento de Recursos Hídricos. 2.ed. Porto Alegre: Editora da UFRGS/Associação Brasileira de Recursos Hídricos, 2002.

BRASIL. Lei n. 9.433, 8 de janeiro de 1997. Presidência da República: Casa Civil. Disponível em: <http://www.planalto.gov.br/ccivil_03/LEIS/L9433.htm>. Acesso em: 04 fev. 2011.

BRÜSEKE, F. J. O Problema do Desenvolvimento Sustentável. In: CAVALCANTI, Clóvis (Org). Desenvolvimento e Natureza: Estudos para uma Sociedade Sustentável. 5. ed. São Paulo: Cortez; Recife, PE: Fundação Joaquim Nabuco, 2009.

CÂNDIDO, G. A. et al. Índice de Desenvolvimento Sustentável para Municípios: Uma Proposta de Metodologia com Participação de Atores Sociais e Institucionais. In: CÂNDIDO, G. A. (Org.) Desenvolvimento Sustentável e Sistemas de Indicadores de Sustentabilidade: Formas de aplicações em contextos geográficos diversos e contingências específicas. Campina Grande, PB: Ed. UFCG, 2010. 
CARVALHO, G. S. de; MINGOTI, S. A. Manual do usuário: programas para realização da Análise Hierárquica. Belo Horizonte: Departamento de Estatística. UFMG, 2005.

\section{CAVASSIN, S. A. Uso de Metodologias Multicritério na Avaliação de} Municípios do Paraná com Base no Îndice de Desenvolvimento Humano Municipal. 2004. Dissertação (Mestrado em Métodos Numéricos em Engenharia - Programação Matemática) - Programa de Pós-Graduação em Métodos Numéricos em Engenharia - Programação Matemática, Setores de Tecnologia e Ciências Exatas, Universidade Federal do Paraná, Curitiba, 2004.

CASTRO, L.M.A. et al. Análise Multicritério para avaliação de sistemas de drenagem urbana: proposição de indicadores e de sistemática de estudo. Revista RBRH, v. 19, n. 4, p.5-19, 2004.

COSTA, H. G. et al. Avaliação da Produção Docente: Abordagem Multicritério pelo Método Electre II. In: ENEGEP, 26, 2006, Fortaleza. Anais... Fortaleza, CE, Brasil: UFCE, 9 a 11 de outubro de 2006.

CURI, W. F.; CURI, R. C. Análise Multicriterial. Slides da disciplina de Otimização em Recursos Naturais (Slides). (Doutorado em Recursos Naturais) - Programa de Pós-Graduação em Recursos Naturais Universidade Federal de Campina Grande, Campina Grande-PB, Ago/Out, 2010.

. Método AHP - Analytic Hierarchy Process. Slides da disciplina de Otimização em Recursos Naturais (Slides). Programa de Pós-Graduação em Recursos Naturais (Doutorado) - Universidade Federal de Campina Grande, Campina Grande-PB, ago/out, 2010.

FARIAS, T. Introdução ao Direito Ambiental. Belo Horizonte: Del Rey, 2009.

GARCIAS, C. M. Indicadores de Qualidade Ambiental Urbana. In: MAIA, Nilson Borlina; MARTOS, Lesjak; BARELLA, Walter. (Orgs.). Indicadores Ambientais: conceitos e aplicações. São Paulo: EDUC/ COMPED/INEP, 2001. 
GODARD, O. A Gestão Integrada dos Recursos Naturais e do Meio Ambiente: Conceitos, Instituições e Desafios de Legitimação. In: VIEIRA, P. F.; WEBER, J. (Orgs.). Gestão de Recursos Naturais Renováveis e Desenvolvimento: novos desafios para a Pesquisa Ambiental. Tradução: Anne Sophie de Pontbriand Vieira, Christilla de Lassus. 3. ed. São Paulo: Cortez, 2002

GOMES, L. F. A. M. et al. Tomada de Decisão Gerencial: enfoque multicritério. 3. Ed. Revista e Ampliada. São Paulo: Atlas, 2009.

GOMES, L. F. A. M. et al. Tomada de Decisão em Cenários Complexos. Introdução aos Métodos Discretos do Apoio Multicritério à Decisão. Tradutora Técnica Marcella Cecília Gonzáles Araya. São Paulo: Pioneira Thomson Learning, 2004.

GUIMARÃES, L. T. Proposta de um Sistema de Indicadores de Desenvolvimento Sustentável para Bacias Hidrográficas. 2008. Tese (Doutorado em Engenharia) - Programa de Pós-graduação de Engenharia da Universidade Federal do Rio de Janeiro, Rio de Janeiro, 2008.

HIGGINS, P.; TRULIO, L. Developing Watershed Indicators for Santa Clara County: A Report to the Santa Clara Valley Water District. Watershed Stewardship Grant Program, 2003. Disponível em: <http://www. svep.org/2004/Dev_Watershed_Indicators.pdf>. Acesso em: 23 fev. 2011.

IUDÍCIBUS, S. de. Teoria da Contabilidade. 7. ed. São Paulo: Atlas, 2004.

JACOBI, P. R. Gestão Participativa dos Recursos Hídricos: reflexões sobre as novas institucionalidades. [Texto apresentado na Secretaria de Meio Ambiente do Estado de São Paulo - Agosto de 2005]. Disponível em: <http://www.teia. fe.usp.br/biblioteca_virtual/AGUA\%201-\%20Gestao\%20Participativa\%20 Recursos\%20Hidricos\%20Jacobi.pdf>. Acesso em: 02 fev. 2011.

JARDIM, S. B. Aplicabilidade de Algumas Técnicas de Análise Multiobjetivo ao Processo Decisório no Âmbito de Comitês de Gerenciamento de Bacia Hidrográfica. 1999. Dissertação (Mestrado em Engenharia dos Recursos Hídricos e Saneamento Ambiental) - Programa de Pós-Graduação em Engenharia dos Recursos Hídricos e Saneamento Ambiental. Porto Alegre, 1999. 
JOLLIVET, M.; PAVÉ, A. Meio Ambiente: Questões e perspectivas para a pesquisa. In: VIEIRA, P. F.; WEBER, J. Gestão de Recursos Naturais Renováveis e Desenvolvimento: Novos Desafios para a Pesquisa Ambiental. São Paulo: Cortez, 2002.

\section{LACHTERMACHER, G. Pesquisa Operacional na Tomada de} Decisões: Modelagem em Excel para os Cursos de Administração, Economia e Ciências Contábeis. Revisão Luiz Flávio A. M. Gomes. Editora Campus, Rio de Janeiro, RJ - 2002.

LANNA, A. E. L. Introdução. In: PORTO, R. L. L. et al. (Orgs.). Técnicas quantitativas para o Gerenciamento de Recursos Hídricos. 2. ed. Porto Alegre: Editora UFRGS - Associação Brasileira de Recursos Hídricos, 2002.

LEFF, H. Complexidade, Interdisciplinaridade e Saber Ambiental. In: PHILIPPI JR. A. et al. (Orgs.) Interdisciplinaridade em Ciências Ambientais. São Paulo: Signus Editora, 2000.

LIMEIRA, M. C. M. Capacitação social como estratégia para restauração de rios: gestão adaptativa e sustentável. 2008, 297 f. Tese (Doutorado em Recursos Naturais) - Programa de Pós-Graduação em Recursos Naturais. Universidade Federal de Campina Grande, Campina Grande, 2008.

LIMEIRA, M. C. M. et al. Gestão Adaptativa e Sustentável para a Restauração de Rios: Parte I. Revista Brasileira de Recursos Hídricos, v. 15, n.1, jan/mar 2010 .

LIRA, W. S. Sistema de Gestão do Conhecimento para Indicadores de Sustentabilidade - SIGECIS: Proposta de uma metodologia Campina Grande - PB. 2008. Tese (Doutorado em Recursos Naturais) - Universidade Federal de Campina Grande. Programa de Pós-Graduação em Recursos Naturais, 2008.

LUCENA, Luciana de Figueiredo Lopes. A Análise Multicriteiral na Avaliação de Impactos Ambientais. In: ENCONTRO DA SOCIEDADE BRASILEIRA DE ECONOMIA ECOLÓGICA, 3, 1999, Recife. Anais... Recife - PE,: SBEE, 1999. 
LYRA, L. W. C. de. Análise Hierárquica dos Indicadores Contábeis sob a Óptica do Desempenho Empresarial. 2008. Tese (Doutorado em Contabilidade e Atuária) - Departamento de Contabilidade e Atuária da Faculdade de Economia, Administração e Contabilidade - Universidade de São Paulo, 2008.

MACHADO, J. 10 Anos da Lei 9433: avanços e dificuldades. In: SIMPÓSIO BRASILEIRO DE RECURSOS HÍDRICOS, 17, 2007, São Paulo. Anais... São Paulo: ABRH, 2007.

MAGALHÃES JÚNIOR, A. P. et al. Os Indicadores como Instrumentos Potenciais de Gestão das Águas no Contexto Legal-Institucional do Brasil - Resultado de um Painel de Especialistas. Revista Brasileira de Recursos Hídricos. v. 8, n. 9, p.49-67, out/dez, 2003.

MAGALHÃES JÚNIOR, A. P. Indicadores Ambientais e Recursos Hídricos: Realidade e Perspectivas para o Brasil a partir da Experiência Francesa. 2. ed. Editora Bertrand Brasil, 2010.

MORAES, E. A. de; SANTALIESTRA, R. Modelo de decisão com múltiplos critérios para escolha de software de código aberto e software de código fechado. In... ENCONTRO DA ANPAD. 31, 2007, Rio de Janeiro 22 a 26 de setembro de 2007. Anais... Rio de Janeiro; ANPAD, 2007.

OLLAGNON, H. Estratégia Patrimonial para a Gestão dos Recursos e dos Meios Naturais: Enfoque Integrado da Gestão do Meio Rural. In: VIEIRA, P. F.; WEBER, J. (Orgs.). Gestão de Recursos Naturais Renováveis e Desenvolvimento: Novos Desafios para a Pesquisa Ambiental. Tradução Anne Sophie de Pontbriand Vieira, Christilla de Lassus. 3. ed. São Paulo: Cortez, 2002.

POLICARPO, M. A.; SANTOS, C. R. dos. Proposta Metodológica de uma Gestão Integrada e Participativa dos Recursos Naturais de Uso Comum: A Contribuição da Análise Trade-Off. REA - Revista de Estudos Ambientais - FURB. v.10, n. 2, p. 71-87, jul./dez. 2008.

POMPERMAYER, R. de S. Aplicação da Análise Multicritério em Gestão de Recursos Hídricos: Simulação para as Bacias dos Rios Piracicaba, Capivari e Jundiaí. Dissertação (Mestrado em Engenharia 
Agrícola) - Universidade Estadual de Campinas, Faculdade de Engenharia Agrícola. Campinas, SP, 2003.

RANGEL, L. A. D. et al. Decision Theory With Multiple Criteria: An Application of Electre IV and Todim to SEBRAE/RJ. Revista Pesquisa Operacional, v.29, n.3, p.577-590, setembro a dezembro de 2009.

SACHS, Ignacy. Caminhos para o Desenvolvimento Sustentável. Rio de Janeiro: Garamond, 2000.

SILVA, J. T. M.; et al. Aplicação do Método de Análise Hierárquica no Processo de Tomada de Decisão: Um Estudo com o Empreendedor Agrícola da Região de Divino/MG. Revista de Gestão e Planejamento. v. 7, n. 14, Salvador/BA, jul - dez/2006.

SILVA, A. C.; et al. Avaliação do desempenho de setores econômicos brasileiros: uma abordagem quantitativa. In: do XIV CONGRESSO BRASILEIRO DE CUSTOS. 14, 2007, João Pessoa. Anais eletrônicos... João Pessoa, PB, 2007.

SILVA, A. M. da. et al. Ecological Footprint Method: Avaliação da Sustentabilidade no Município de João Pessoa, PB. In: CÂNDIDO, G. A. Desenvolvimento Sustentável e Sistemas de Indicadores de Sustentabilidade: Formas de aplicações em contextos geográficos diversos e contingências específicas. Campina Grande, PB: Ed. UFCG, 2010.

SOARES, M. A. Análise de indicadores para avaliação de desempenho econômico-financeiro de operadoras de planos de saúde brasileiras: uma aplicação da análise fatorial. 2006. 122.f. Dissertação (Mestrado em Ciências Contábeis) - Programa de Pós-Graduação em Controladoria e Contabilidade. Universidade de São Paulo: São Paulo, 2006.

SOUKI, G. Q.; PEREIRA, C. A. Satisfação, Motivação e Comprometimento de Estudantes de Administração: Um Estudo Com Base nos Atributos de uma Instituição de Ensino Superior. In: XXVIII ENCONTRO DO ANPAD. 28, 2004, Curitiba. Anais...Curitiba, PR, 2004. 
TUNSTALL, D. Developing environmental indicators: definitions, framework and issues. Workshop on Global Environmental Indicators, Washington DC, EUA, 1992.

VAN BELLEN, H. M. Indicadores de Sustentabilidade: uma análise comparativa. 2. ed. Rio de Janeiro: FGV, 2006.

VIEIRA, V. P. P. B. Desafios da Gestão Integrada de Recursos Hídricos no Semiárido. RBRH - Revista Brasileira de Recursos Hídricos, v. 8, n.2, p. 7-17, abr/jun 2003.

VIEIRA, P. M. S.; STUDART, T. M. C. Proposta Metodológica para o Desenvolvimento de um Índice de Sustentabilidade Hidro-Ambiental de Áreas Serranas no Semiárido Brasileiro - Estudo de Caso: Maciço de Baturité, Ceará. RBRH - Revista Brasileira de Recursos Hídricos v.14, n.4, p. 125-136, Out/Dez 2009.

VIEIRA, P. F.; WEBER, J. Introdução Geral: Sociedades, Naturezas e Desenvolvimento Viável. In: VIEIRA, P. F.; WEBER, J. (Orgs.). Gestão de Recursos Naturais Renováveis e Desenvolvimento: Novos Desafios para a Pesquisa Ambiental. Tradução Anne Sophie de Pontbriand Vieira, Christilla de Lassus. 3. ed. São Paulo: Cortez, 2002.

WEBER, J. Gestão de Recursos renováveis: Fundamentos Teóricos de um Programa de Pesquisas. In: VIEIRA, P. F.; WEBER, J. (Orgs.). Gestão de Recursos Naturais Renováveis e Desenvolvimento: Novos Desafios para a Pesquisa Ambiental. Tradução Anne Sophie de Pontbriand Vieira, Christilla de Lassus. 3. ed. São Paulo: Cortez, 2002.

ZUFFO, A. C. Seleção e aplicação de métodos multicriteriais ao planejamento ambiental de recursos hídricos. 1998. Tese (Doutorado em Engenharia) - Escola de Engenharia de São Carlos - Universidade de São Paulo, São Carlos/SP, 1998. 